\title{
Modeling and Thermal Performance Evaluation of Porous Curd Layers in Sub-Cooled Boiling Region of PWRs and Effects of Sub-Cooled Nucleate Boiling on Anomalous Porous Crud Deposition on Fuel Pin Surfaces
}

\author{
P. I.: \\ Barclay G. Jones \\ Students: \\ Dawei Zhou \\ Hyun-jong Joe \\ Qinyang Rao \\ Srinivasan Radhakrishnan \\ Wen $\mathrm{Wu}$ \\ Department Nuclear, Plasma, and Radiological Engineering \\ University of Illinois at Urbana-Champaign
}

June 27, 2005

Urbana, Illinois 


\section{ACKNOWLEDGEMENT}

The sponsorship of this research by the United States Department of Energy under Research Contract - DOE DEFG07-00ID13924 (DOE NEER-Jones) is sincerely appreciated. Additionally, support from the Department of Nuclear, Plasma and Radiological Engineering of the University of Illinois at Urban-Champaign is gratefully acknowledged. 


\section{BACKGROUND INTRODUCTION}

A Significant number of current PWRs around the world are experiencing anomalous crud deposition in the sub-cooled boiling region of the core, resulting in an axial power shift or Axial Offset Anomaly (AOA), a condition that continues to elude prediction of occurrence and thermal/neutronic performance. This creates an operational difficulty of not being able to accurately determine power safety margin. In some cases this condition has required power 'down rating' by as much as thirty percent and the concomitant considerable loss of revenue for the utility. This study examines two aspects of the issue: thermal performance of crud layer and effect of sub-cooled nucleate boiling on the solute concentration and its influence on initiation of crud deposition/formation on fuel pin surface.

At present there are no models which predict crud formation, but there are ample experimental observations of the crud layer and its material composition and structure. There are, however, several models in the literature that attempt to evaluate thermal performance, and some of these estimate the holdup of solute containing boron and boron compounds in the crud layer. There is little or no benchmarking of these models with available plant data or other experimental observations. We previously developed a two-dimensional model, primarily for corrosion considerations, which enables detailed thermal performance to be evaluated and which predicts concentration levels of soluble holdup. However, there is evidence from plant performance suggesting that precipitation of the solute, particularly boron and boron compounds, occurs and needs to be considered. Thus one focus of this research is to revisit the model and to incorporate precipitation mechanisms in it to account for these observations. The results of the model will be benchmarked with observed power shifts from plant data.

The other focus of this research is to examine solute concentration distributions at the sub-cooled nucleation sites prior to crud formation where the bubble interface with the wall and its evaporative pumping action provides a pathway for water vapor and other gases present from boiling and radiolysis of water to be moved into the bubble and to be stripped form the region. Simultaneously this concentrates solutes in the water at the bubble attachment/wall surface region that may lead to their precipitation on and attachment to the surface, thereby initiate crud deposition. Both foci draw heavily on earlier PI research. 


\section{NOMENCLATURE}

c: $\quad$ specific heat

$\mathrm{C}$ : local solute concentration in the porous shell

$\mathrm{C}_{b}$ : boron concentration in bulk coolant.

$D$ : diffusion coefficient of boron in water

E: $\quad$ evaporation or condensation coefficient

$F$ : $\quad$ Fast neutron fluence

G: $\quad$ Yields of radiolysis (\# of molecules $/ 100 \mathrm{eV}$ )

$\mathrm{h}$ : $\quad$ interfacial heat transfer coefficient at the bubble interface

$\left[\mathrm{H}_{2} \mathrm{O}_{2}\right]_{\mathrm{st}}$ : Stationary $\mathrm{H}_{2} \mathrm{O}_{2}$ concentration

$M$ : $\quad$ A factor considering the metallurgical state

MWD/MTU Burnup in Megawatt Days/Metric Ton

$N_{v}: \quad$ chimney density $\left(\# / \mathrm{m}^{2}\right)$

$\left[\mathrm{O}_{2}\right]$ : $\quad$ Oxygen concentration in the coolant

$\mathrm{P}_{\mathrm{O} 2}$ : $\quad$ Partial oxygen pressure in oxide matrix

Q: $\quad$ Heat flux (W/cm2)

R: $\quad$ Gas constant

$r_{v}: \quad$ chimney radius (um)

S: $\quad$ A factor considering the condition of the alloy surface

$\mathrm{T}$ : $\quad$ Absolute temperature at coolant clad interface

$\mathrm{T}_{\mathrm{L}}$ : $\quad$ Temperature of laminar layer

$\mathrm{T}_{\text {Met }}$ : $\quad$ Temperature of the metal

$\mathrm{T}_{\mathrm{RZ}}$ : $\quad$ Temperature of reaction zone

$\mathrm{V}_{\text {unif: }} \quad$ Uniform oxidation rate

W: $\quad$ Weight loss component

$\mathrm{W}_{\mathrm{F}}$ : $\quad$ Radiation weight loss component

$\mathrm{W}_{\mathrm{T}}$ : Thermal weight loss component

$\mathrm{e}_{\alpha}$ : $\quad$ Electron produced at the matrix metal/matrix oxide $\left(\mathrm{ZrO}_{2}\right)$ interface

$\mathrm{e}_{\beta}$ : $\quad$ Electron consumed by the proton at the matrix oxide $\left(\mathrm{ZrO}_{2}\right) /$ steam

(gas) interface

$\mathrm{k}_{0}$ : $\quad$ Initial corrosion coefficient ()

$\mathrm{k}_{\mathrm{F}}$ : $\quad$ Radiation corrosion coefficient

$\mathrm{k}_{\mathrm{T}}$ : Thermal corrosion coefficient

$\lambda_{2}: \quad$ Thermal conductivity

$\delta: \quad$ crud thickness (um)

$\varepsilon: \quad$ porosity of the porous shell 
This report, which presents deliverables and discussions for Research Contract - DOE DEFG07-00ID13924 (DOE NEER-Jones), is divided into two main sections: Part A, which focuses on predictive performance of anomalous crud layers on fuel pins and their comparison with field data on axial offset anomaly (AOA)from operating PWR power plants and Part B, which focuses on determination of the influence of bubbles attached to fuel pin surfaces in sub-cooled boiling on creating the necessary environment for crud deposition. Each section includes the three years of research and development, referred to as Phases. The results and conclusions are incorporated in the discussion in each Phase. A separate listing of published papers is presented at the end of report. References for the whole report are listed at the end of the report. Figures and Tables are incorporated in the text. 


\section{PART A - Predictive Performance Of Anomalous Crud Layers On Fuel Pins And Their Comparison With Field Data On Axial Offset Anomaly (AOA) From Operating PWR Power Plants}

\section{PHASE I}

The presence of the crud layer and the associated accumulation of high concentrations of neutron absorber (boron or boron compounds) within it result in an axial shift of the core power profile. Normally in the core of pressurized water reactors (PWR), the upper central part experiences sub-cooled boiling due to the heat flux distribution and flow field. Fig. 1 shows the described sub-cooled boiling region. This sub-cooled boiling region coincides with the region of porous crud deposition on the fuel rod surfaces (Fig. 2), and accumulation of boron. Because boron is a very strong neutron absorber, boron holdup on the PWR fuel pin can be sufficient to result in AOA and thus create an operational difficulty of being unable to accurately determine safety margin. The task of this study is to build a thermal performance and boron concentration model of the crud layer and to calculate the amount of boron holdup in the sub-cooled boiling region.

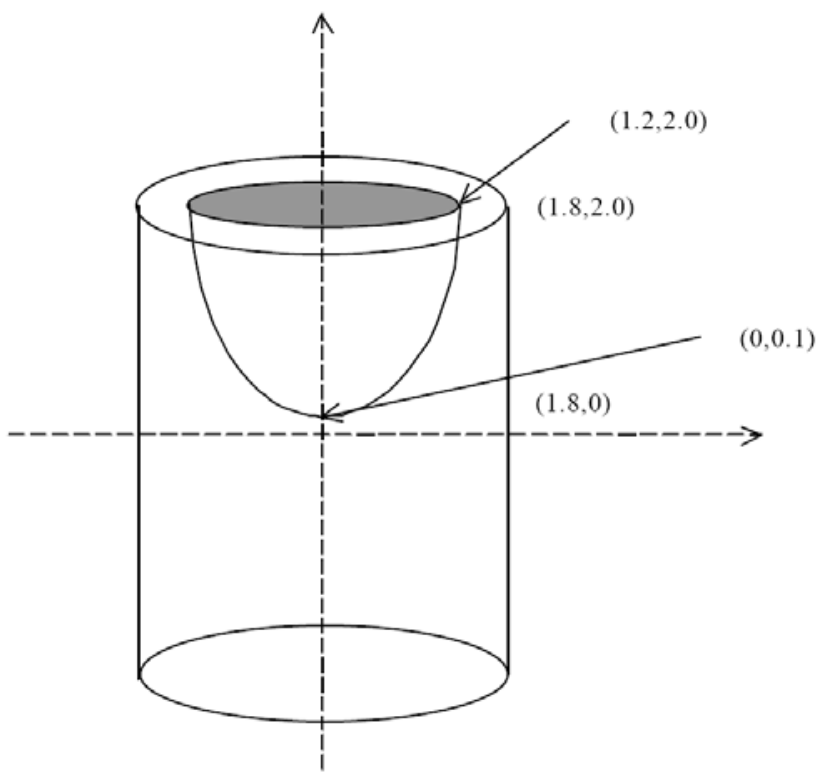

Fig. 1. Sub-Cooling Area in the PWR Core 


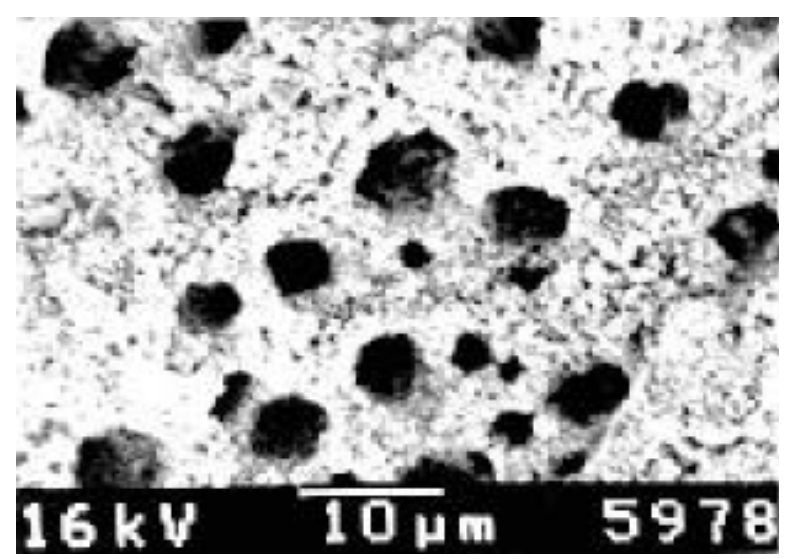

Fig. 2. Porous Deposition on the Fuel Pin (Enlarged)

\section{NUMERICAL MODEL AND PROCEDURE}

The uniform chimney distribution shown in Fig. 2 enables consideration of a unit cell with a central chimney and a surrounding porous medium. For a square lattice of chimneys, an equivalent cylindrical region approximates the surrounding porous region.

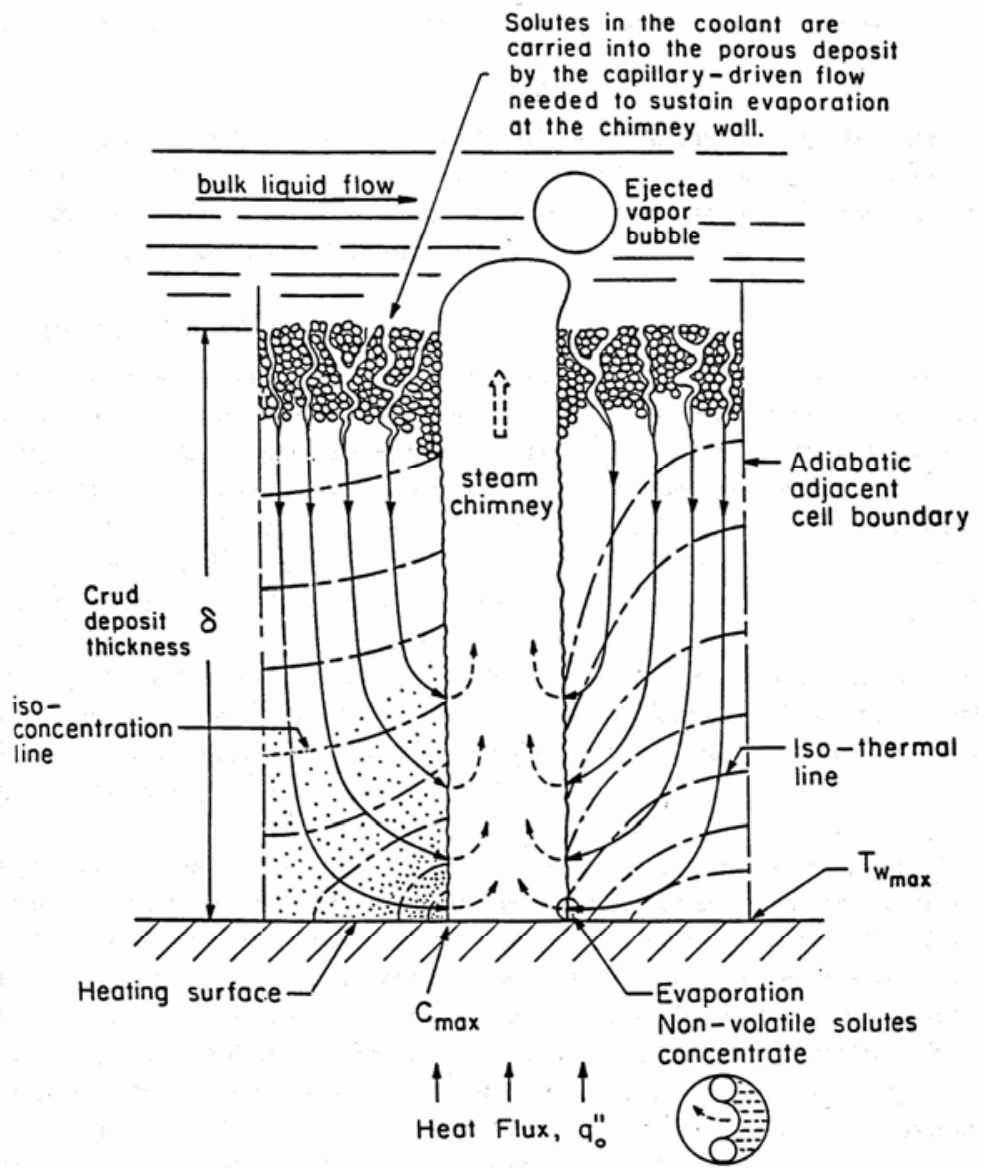

Fig. 3. Schematic of the Wick Boiling in the Unit Cell 
Thus, the model development is based on the transport of heat, momentum and solutes within this cylindrical unit cell, including radial and axial dependence $[1,2]$ (Fig. 3). The numerical analysis for the problem of interest is based on the two-dimensional model of Jones, Pan and Sun (1984) [3]. The utilized model is a mathematically equivalent but revised to calculate boron component holdup. The central idea underlying the model is to solve the solute distribution in the porous crud layer coupled with energy and momentum equations and then to calculate the holdup of the boron. By assuming that the imposed heat flux is entirely removed by the latent energy transport at the chimney wall and the porous structure surrounding the chimney is isotropic, a set of conservation equations and boundary conditions are derived and are summarized in Fig. 4. The reader is referred to reference [3] for a detailed derivation of the equations and explanation the of physical meaning of the various quantities.

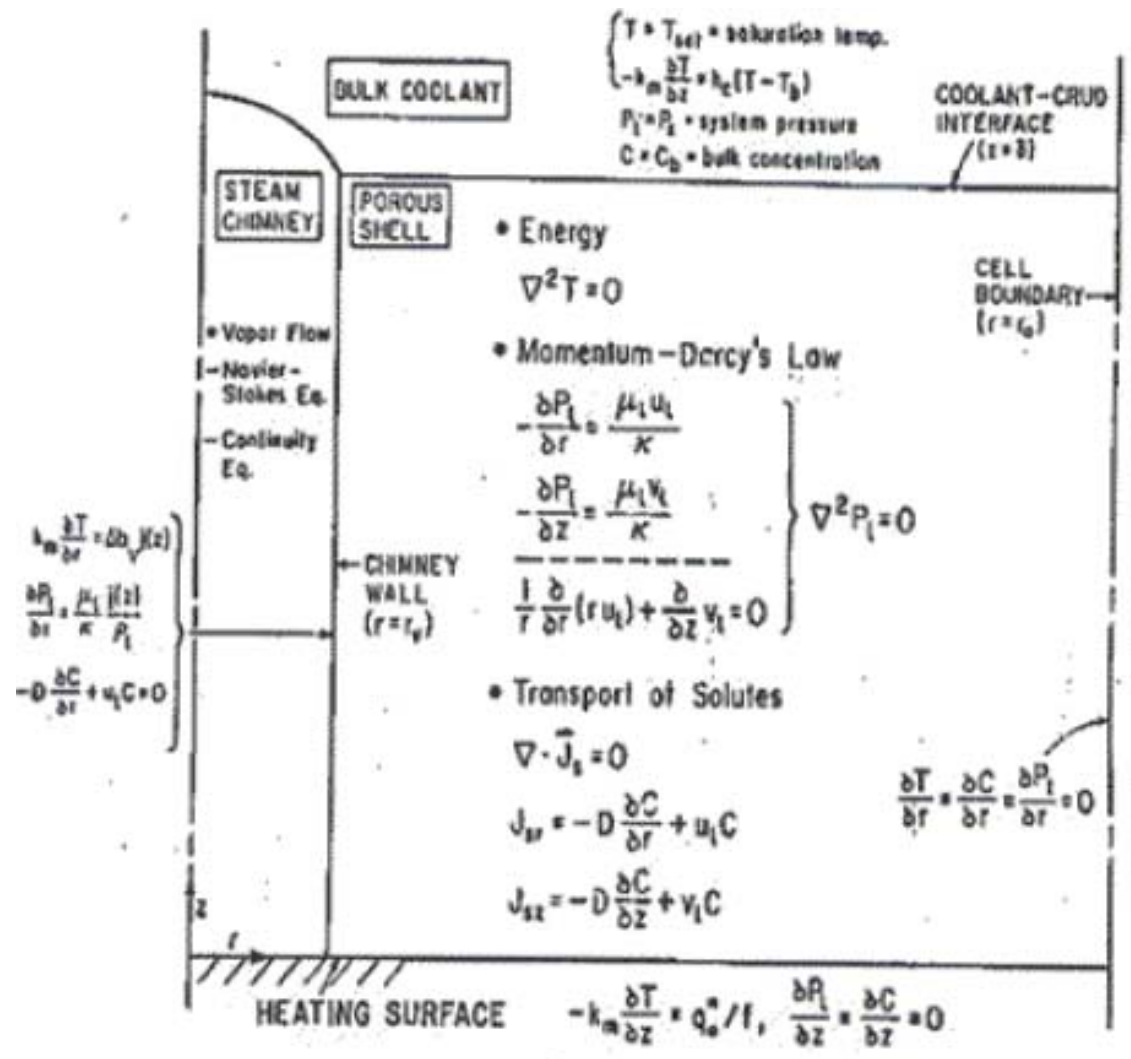

Fig. 4. Conservation Equations and Boundary Conditions

An iterative procedure has been developed to solve the set of coupled equations and convergence is enforced with the criterion that relative errors between iterations in both the enthalpy and velocity fields be less than $10^{-6}$. For simplicity, uniform and fixed grids were chosen. A typical run based on $82 \times 82$-grid system requires a CPU time of approximately 10 minutes on a Pentium III PC. Using the reference case, which is $\mathrm{N}_{\mathrm{v}}=6000$ chimneys $/ \mathrm{mm}^{2}, \mathrm{r}_{\mathrm{v}}=2.5 \mathrm{um}, \mathrm{e}=0.58, \mathrm{P}=2297 \mathrm{psi}, \mathrm{q}_{0}=1.0$ $\mathrm{MW} / \mathrm{m}^{2}$, the solute $\left(\mathrm{H}_{3} \mathrm{BO}_{3}\right)$ concentration distribution in the unit cell is calculated 
and the result is shown in Fig. 5. As shown, more boric acid resides at the bottom of the unit cell. This result strongly supports the point that sufficient boron accumulates in the crud layer to causes the observed power shift.

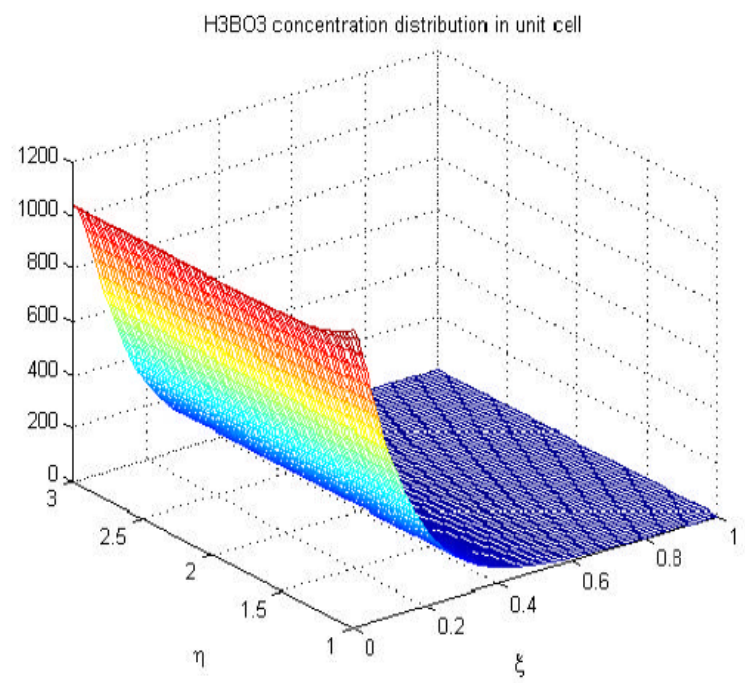

Fig.5. H3BO3 concentration distribution in the unit cell

Fig. 5. $\mathrm{H}_{3} \mathrm{BO}_{3}$ Concentration Distribution in the Unit Cell

\section{A-a) Benchmark comparison of existing model with Callaway field data}

\section{i). Estimation of boron holdup in crud layer in sub-cool boiling region}

After calculating of the solute distribution in the unit cell, the local average solute concentration, f, can be determined. According to ref. [4], the volume of porous deposit in unit channel length is

$$
V_{p}=\pi d \delta \varepsilon=3.1415 \times 9.5 \times 10^{-3} \times 85 \times 10^{-6} \times 0.6=1.51 \times 10^{-6}\left(\mathrm{~m}^{3}\right)
$$

The amount of boron in the crud is:

$$
N=V_{p} C_{b} \phi \rho_{\mathrm{H}_{2} \mathrm{O}}=1.51 \times 10^{-6} \times 700 \mathrm{ppm} \times 32.2 \times 0.721 \times 10^{3}=2.30 \times 10^{-5}(\mathrm{~kg})
$$

Where the value of $\phi$ is from [4].

$\delta=85 \mu \mathrm{m} ; C_{b}=700 \mathrm{ppm} ; \rho_{\mathrm{H}_{2} \mathrm{O}}=0.721 \times 10^{3} \mathrm{~kg} / \mathrm{m}^{3}$

$\phi=\frac{\Sigma V_{i} \phi_{i}}{V}=32.2 \quad$ (Table. 1$)$ 


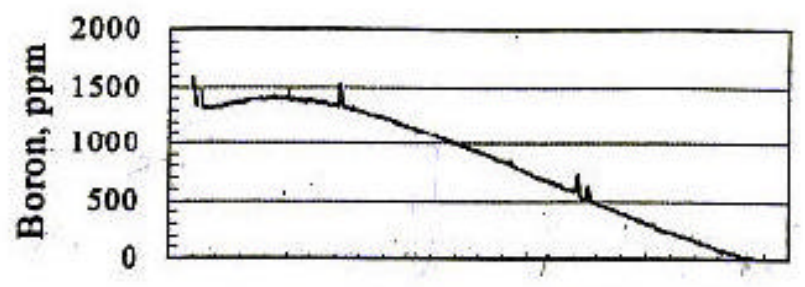

reactor feed fuel burnup (MND/MTU)

Fig. 6. Vary of Bulk Boron Concentration with Feed Fuel Burn-Up[3]

Table. 1. Selected Values of $\phi_{i}$, Local Concentration Factor

\begin{tabular}{l|llc}
\hline Coordinate of point $(r, z)$ & $q^{\prime \prime}\left(w / m^{3}\right)$ & $q^{\prime \prime}\left(w / m^{2}\right)$ & $\begin{array}{c}\text { Local solute concentration } \\
\text { factor } \phi_{i}\end{array}$ \\
\hline$(0,0.1)$ & $1.258 \times 10^{9}$ & $2.23 \times 10^{6}$ & 95 \\
$(0,0.3)$ & $1.227 \times 10^{9}$ & $2.17 \times 10^{6}$ & 84 \\
$(0,0.5)$ & $1.116 \times 10^{9}$ & $2.06 \times 10^{6}$ & 66 \\
$(0,0.7)$ & $1.076 \times 10^{9}$ & $1.90 \times 10^{6}$ & 46 \\
$(0,0.9)$ & $9.601 \times 10^{8}$ & $1.70 \times 10^{6}$ & 29 \\
$(0,1.1)$ & $8.202 \times 10^{8}$ & $1.45 \times 10^{6}$ & 17 \\
$(0,1.3)$ & $6.601 \times 10^{8}$ & $1.17 \times 10^{6}$ & 9 \\
$(0.2,0.3)$ & $1.206 \times 10^{9}$ & $2.15 \times 10^{6}$ & 80 \\
$(0.2,0.5)$ & $1.145 \times 10^{9}$ & $2.04 \times 10^{6}$ & 63 \\
$(0.2,0.7)$ & $1.057 \times 10^{9}$ & $1.89 \times 10^{6}$ & 44 \\
$(0.2,0.9)$ & $9.430 \times 10^{8}$ & $1.68 \times 10^{6}$ & 28 \\
$(0.4,0.5)$ & $1.084 \times 10^{9}$ & $1.98 \times 10^{6}$ & 55 \\
$(0.4,0.9)$ & $8.927 \times 10^{8}$ & $1.63 \times 10^{6}$ & 25 \\
$(0.6,0.9)$ & $8.119 \times 10^{8}$ & $1.55 \times 10^{6}$ & 21 \\
$(0.8,1.1)$ & $6.021 \times 10^{8}$ & $1.22 \times 10^{6}$ & 10 \\
\hline
\end{tabular}

The total amount of Boron holdup in the crud layer is:

$$
M=N L N u m(V / V t)
$$

where: $\mathrm{L}=2.0-0.1=1.9 \mathrm{~m}$

$$
\begin{aligned}
& \text { Num }=\frac{S}{l^{2}}=\frac{3.1415926 \times 1.8^{2}}{\left(12.6 \times 10^{-3}\right)^{2}}=6.41 \times 10^{4} \\
& V=4.29\left(\mathrm{~m}^{3}\right)(\text { Volume of the parabolic-shape area) } \\
& V_{t}=\pi \times 1.8^{2} \times(2.0-0.1)=19.34\left(\mathrm{~m}^{3}\right)
\end{aligned}
$$

So, $M=\operatorname{NLNum}(V / V t)=0.66(\mathrm{~kg})$ 


\section{ii). Boron holdup calculation using Callaway data set}

A further Boron holdup calculation, using plant data from Callaway Cycles 6, 9 [3, 4] is made below. There are 193 total fuel channels in the core. Only channels with sub-cool boiling are used for the calculation. According to ref. [1], the volume of porous deposit in a unit channel length is:

$$
V_{p}=\pi d \delta \varepsilon
$$

where: $\delta$ is the crud thickness; $d=9.5 \mathrm{~mm}$ is the fuel pin diameter

The amount of boron in the crud is:

$$
a=V_{p} C_{b} \bar{\phi} \rho_{\mathrm{H}_{2} \mathrm{O}}
$$

where, the bulk coolant, solute concentration, $C_{b}$, is obtained from Fig. 2;

$\rho_{\mathrm{H}_{2} \mathrm{O}}=0.721 \times 10^{3}\left(\mathrm{~kg} / \mathrm{m}^{3}\right) ; \bar{\phi}$ is the average solute concentration in the crud for each node, which is calculated by using the existing model.

The amount of boron in each node is:

$$
n_{i}=a \Delta z_{i}
$$

where: $\Delta z_{i}$ is the length of the fuel pin node, which equals $4.32 \mathrm{~cm}(1.7$ ').

The total amount of boron in one channel is:

$$
N=\Sigma n_{i}
$$

Thus, the total amount boron is obtained for several different crud thickness, $\delta$, as is shown in the following tables, Table. 2, Table. 3, and Table. 4, using the field data for three specific Callaway cycles and burnup levels.

Table. 2. Callaway Cycle 9 800MWD/MTU

\begin{tabular}{cc}
\hline $\begin{array}{c}\text { Crud } \\
\text { Thickness } \\
\text { (um) }\end{array}$ & $\begin{array}{c}\text { Boron Holdup } \\
\text { (total) }\end{array}$ \\
\hline 85 & $(\mathrm{~kg})$ \\
90 & 0.06494 \\
100 & 0.126 \\
105 & 0.4632 \\
110 & 0.895 \\
\hline
\end{tabular}


Table. 3. Callaway Cycle 9 400MWD/MTU

\begin{tabular}{cc}
\hline $\begin{array}{c}\text { Crud } \\
\text { Thickness } \\
\text { (um) }\end{array}$ & $\begin{array}{c}\text { Boron Holdup (total) } \\
\text { (kg) }\end{array}$ \\
\hline 25 & 0.000105 \\
50 & 0.00495 \\
75 & 0.267 \\
85 & 1.334 \\
\hline
\end{tabular}

Table. 4. Callaway Cycle 6 600MWD/MTU

\begin{tabular}{cc}
\hline $\begin{array}{c}\text { Crud } \\
\text { Thickness } \\
\text { (um) }\end{array}$ & $\begin{array}{c}\text { Boron Holdup (total) } \\
(\mathrm{kg})\end{array}$ \\
\hline 25 & $9.42 \mathrm{E}-5$ \\
50 & 0.03924 \\
75 & 0.1829 \\
85 & 0.8633 \\
\hline
\end{tabular}

\section{iii). Discussion of effects of parameter variation}

a) Effect of Crud Thickness

Observations and analyses show that Boron holdup is very sensitive to crud thickness, varying exponentially. Since at $4000 \mathrm{MWD} / \mathrm{MTU}$, there is almost no power shifting, which means Boron holdup is relatively small, one can assume that the crud thickness is around 50um or less. And according to Dr.Young's interpretation, the crud thickness at $8000 \mathrm{MWD} / \mathrm{MTU}$ is about $100 \mathrm{um}$. 


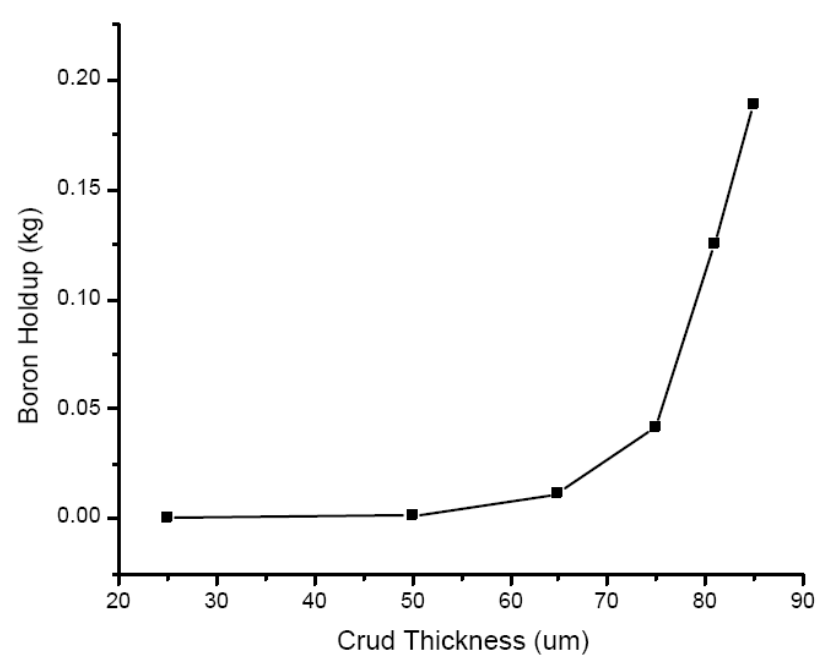

Fig. 7. Effect of Crud Thickness (4000MDW/MTU) $\mathrm{Nv}=6000, \mathrm{rv}=2.5 \mathrm{um}, \quad \varepsilon=0.58, \mathrm{P}=2297 \mathrm{psi}$

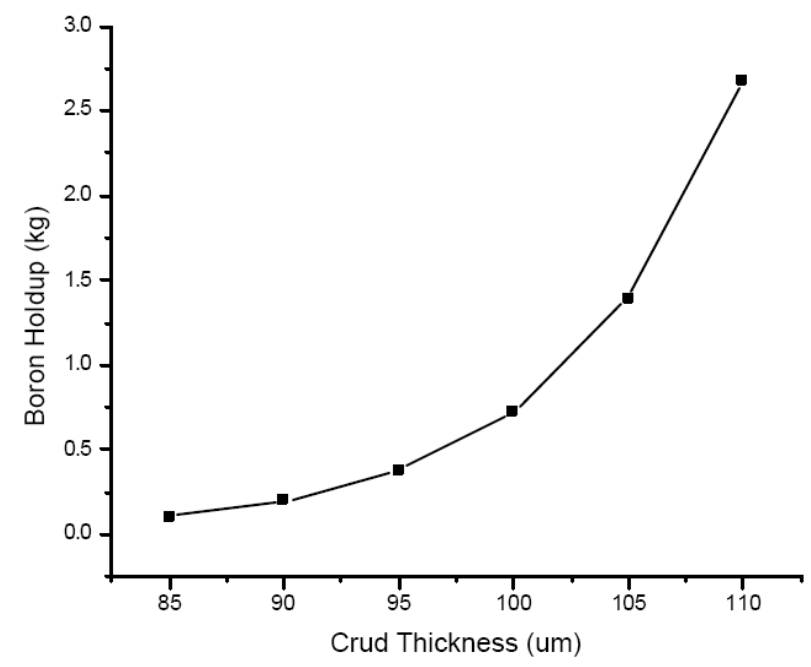

Fig. 8. Effect of Crud Thickness (8000MDW/MTU) $\mathrm{Nv}=6000, \mathrm{rv}=2.5 \mathrm{um}, \quad \varepsilon=0.58, \mathrm{P}=2297 \mathrm{psi}$

Based on this data, crud growth is postulated to behave with an exponential rate, yielding a graph of crud thickness growth with power, shown in Fig. 9 


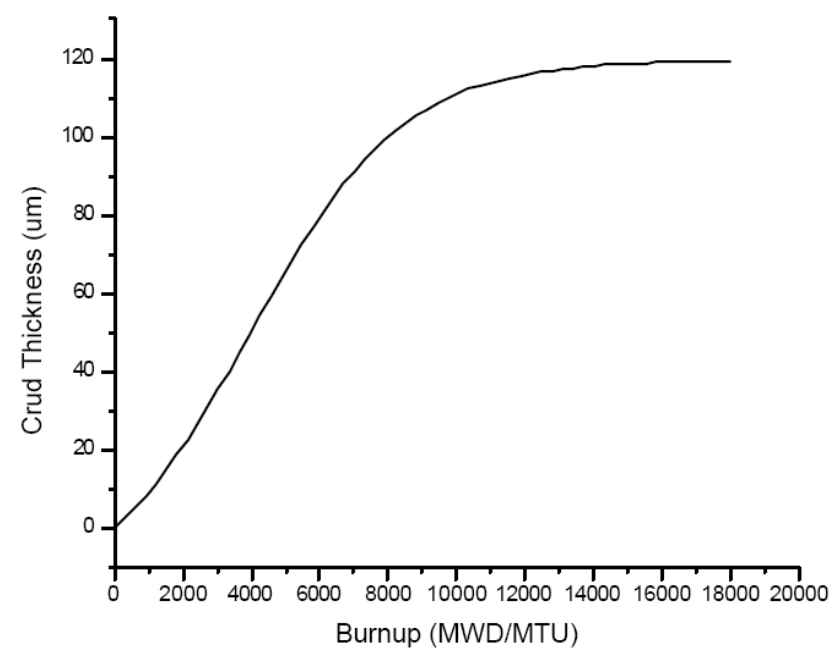

Fig. 9. Crud Thickness Growth

Utilizing this assumption, the boron holdup for Callaway Cycle 9 at a burnup of $4000 \mathrm{MWD} / \mathrm{MTU}$ is $0.00495 \mathrm{~kg}$ and at a burnup $8000 \mathrm{MWD} / \mathrm{MTU}$ is $0.895 \mathrm{~kg}$. This result is consistent with the Callaway field data, which shows that $0.6-0.7 \mathrm{~kg}$ Boron is needed to acquire the observed AOA.

\section{b) Effect of Porosity}

From analysis, Boron holdup is also postulated to be exponentially related to porosity. Calculations, using Callaway observed conditions, are shown in Fig. 10. and Fig. 11. For these evaluations a porosity of $\varepsilon=0.58$ is utilized, which was recommended by Dr. K. Burrill [5].

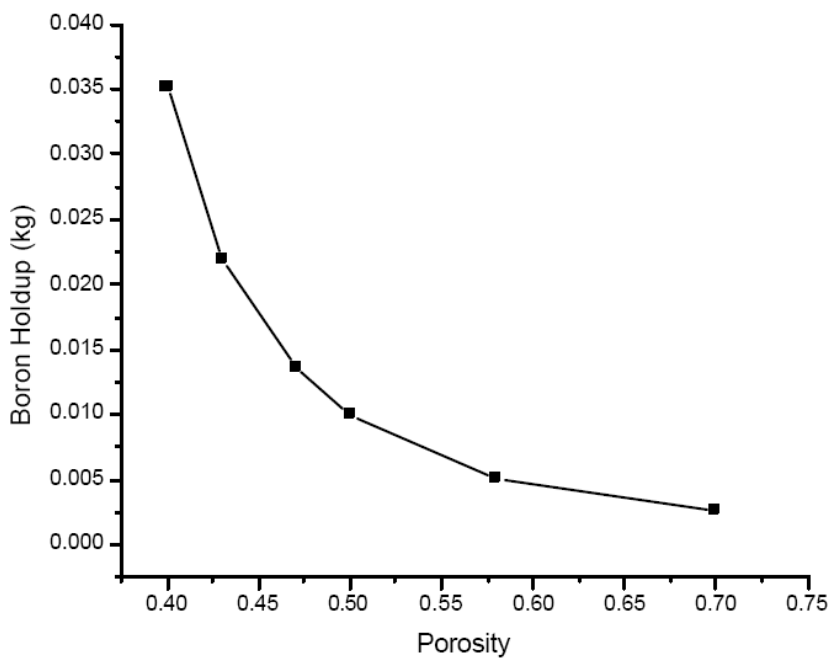

Fig. 10. Effect of Crud Thickness (4000MWD/MTU)

$$
\mathrm{Nv}=6000, \mathrm{rv}=2.5, \delta=50 \mathrm{um}, \mathrm{P}=2279 \mathrm{psi}
$$




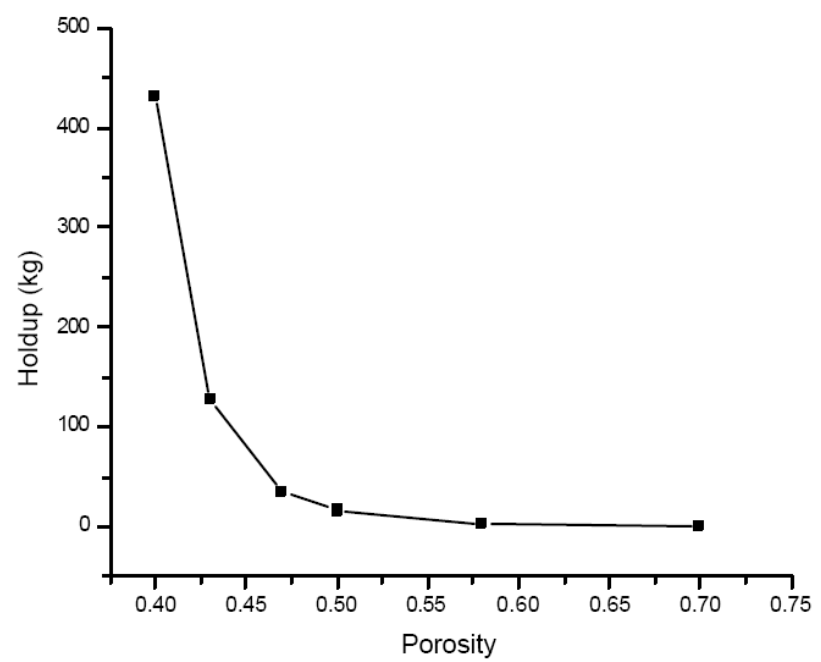

Fig. 11. effect of porosity (8000MWD/MTU) $\mathrm{Nv}=6000, \mathrm{rv}=2.5, \mathrm{~d}=110 \mathrm{um}, \mathrm{P}=2279 \mathrm{psi}$

\section{c) Relative power effect of Boron holdup in the sub-cooled boiling region}

The relative power effect of Boron holdup in the sub-cooled boiling region of the core is assessed by first evaluating the total boron mass in the core for the case of Callaway at a burnup $4000 \mathrm{MWD} / \mathrm{MTU}$ and using the data from Callaway Cycle 9 [3]:

Fuel rod diameter, $\delta=9.5 \mathrm{~mm}$

Cross-section of core: $S=\pi \frac{D^{2}}{4}=10.18\left(\mathrm{~m}^{2}\right)$

Water volume in the core: $V=L\left(S-\pi d^{2} \times 193 \times 17 \times 17 / 4\right)=24.9\left(\mathrm{~m}^{2}\right)$

Mass of water in the core: $M=V \rho=24.91 \times 1.013 \times 10^{3}=2.52 \times 10^{4}(\mathrm{~kg})$

Thus, the Boron in the core is: $M_{b}=2.52 \times 10^{4} \times 1300 \mathrm{ppm}=32.76(\mathrm{~kg})$

From this the ratio of Boron in the crud to that in the bulk coolant is obtained and presented in Table. 5 
Table. 5. Ratio of Boron in Bulk Coolant to Boron in Crud Layer

\begin{tabular}{|l|l|l|l|}
\hline $\begin{array}{l}\text { Burnup } \\
(\mathrm{MWD} / \mathrm{MTU})\end{array}$ & $\begin{array}{l}\text { Boron in Bulk Coolant* } \\
(\mathrm{kg})\end{array}$ & $\begin{array}{l}\text { Boron in crud ** } \\
(\mathrm{kg})\end{array}$ & $\begin{array}{l}\text { Ratio } \\
(\%)\end{array}$ \\
\hline 4000 & 32.76 & 0.001265 & 0.00386 \\
\hline 6000 & 30.57 & 0.489 & 1.6 \\
\hline 8000 & 27.61 & 0.718 & 2.6 \\
\hline 10000 & 22.78 & 0.91 & 4 \\
\hline 12000 & 16.9 & 0.93 & 5.5 \\
\hline 14000 & 13.57 & 0.95 & 7 \\
\hline 16000 & 9.156 & 0.97 & 10.6 \\
\hline 18000 & 5.15 & 1.0 & 19.4 \\
\hline
\end{tabular}

*Data from Fig. 6

**Assuming maximum Boron mass in the crud is $1.0 \mathrm{~kg}$.

This information is also presented in Fig. 12, showing an exponential increase with burnup even with a significant decrease in Boron concentration in the bulk coolant as shown in Fig. 6 and Table. 5.

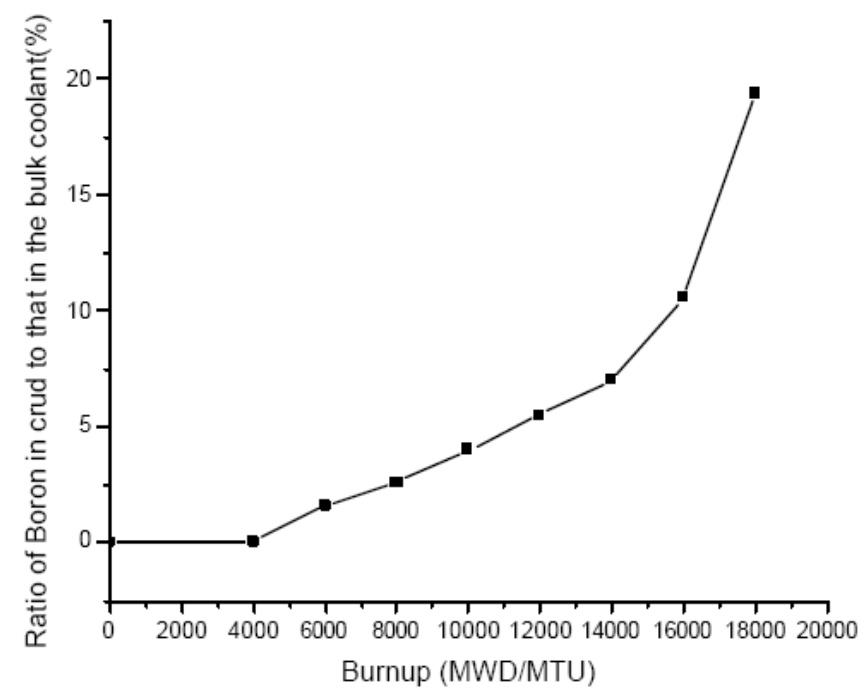

Fig. 12. Ratio of Boron in the Core

Fig. 12 shows that the ratio of Boron in the crud to that in the Bulk coolant is increasing even though the amount of Boron in the crud is holding steady at about $1.0 \mathrm{~kg}$ and its effect on the power shift is increasing

\section{A-b) Thermal-physical data covering range of anticipated materials over operating plant conditions}

Several conditions can impact the behavior of the crud layer and a variety of materials can contribute to Boron holdup and thermal performance. In particular, the relatively high concentration levels of solute species in the bulk coolant in the porous crud layer may led to precipitation in the void region and also to chemical reactions. To assess these possibilities, properties of some prominent species are presented and considered. 
Table. 6. Thermal-physical data of the main anticipated materials

\begin{tabular}{|l|l|l|l|}
\hline Material & Density & Melting point & Solubility \\
\hline Boric Acid & $1.52 \mathrm{~g} / \mathrm{cm} 3$ & $185 \mathrm{C}$ & See the Fig 9 \\
\hline Boron oxide & $2.46 \mathrm{~g} / \mathrm{cm} 3$ & $450 \mathrm{C}$ & See the Fig 9 \\
\hline Lithium Metaborate & $1.40 \mathrm{~g} / \mathrm{cm} 3$ & $845 \mathrm{C}$ & See the Fig 10 \\
\hline Lithum Hydroxide & $1.51 \mathrm{~g} / \mathrm{cm} 3$ & --- & \\
\hline
\end{tabular}

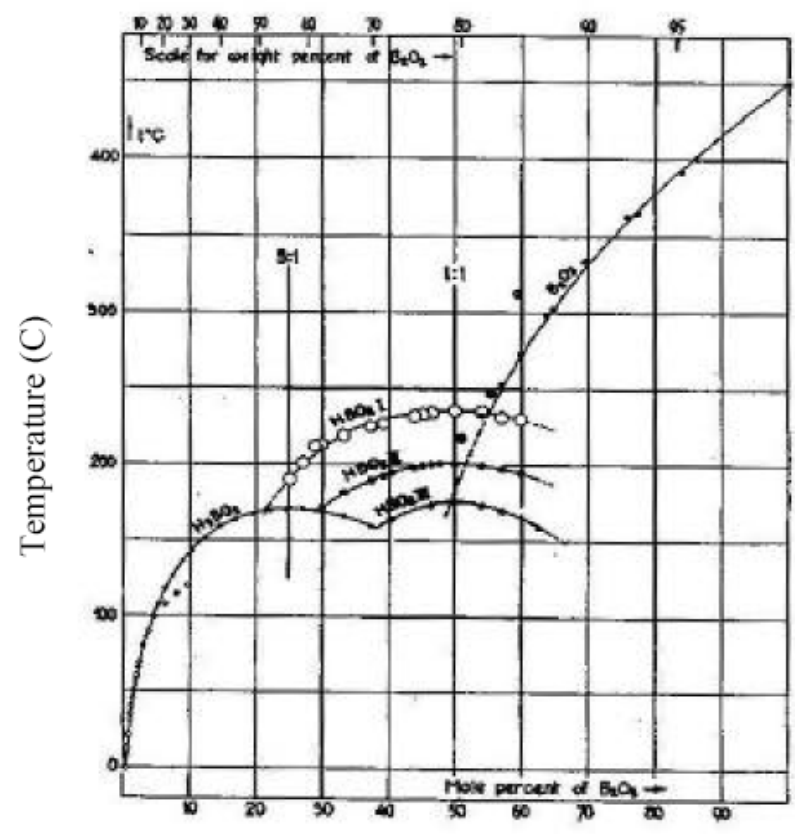

Mole percent of boron oxide

Fig. 13. Solubility Diagram for the System $\mathrm{H}_{2} \mathrm{O}-\mathrm{B}_{2} \mathrm{O}_{3}$ (Ref. $[5,6]$ )

Fig. 13, taken from Kracek et al. [6] shows the solubility curves the $\mathrm{B}_{2} \mathrm{O}_{3}-\mathrm{H}_{2} \mathrm{O}$ system over the whole composition range. The solid phases are $\mathrm{H}_{3} \mathrm{BO}_{3}$ (ortho-boric acid), three monotropic modifications of $\mathrm{HBO}_{2}$ (metaboric acid), and $\mathrm{B}_{2} \mathrm{O}_{3}$. The solubility data of $\mathrm{H}_{3} \mathrm{BO}_{3}$ are presented in [7]. 
Table. 7. Solubility of $\mathrm{H}_{3} \mathrm{BO}_{3}$

\begin{tabular}{|c|c|c|}
\hline Temperature, $\mathrm{C}$ & & $\begin{array}{l}\text { Solubility } \\
\mathrm{g} \mathrm{H} 3 \mathrm{BO} 3 / 100 \mathrm{~g} \text { of Solution in } \mathrm{H} 2 \mathrm{O}\end{array}$ \\
\hline & $\mathrm{P}=1 \mathrm{~atm}$ & \\
\hline 60 & & 12.97 \\
\hline 70 & & 15.75 \\
\hline 80 & & 19.06 \\
\hline 90 & & 23.27 \\
\hline \multirow[t]{2}{*}{100} & & 27.53 \\
\hline & $\mathrm{P}=\mathrm{P}$ sat & \\
\hline 107.8 & & 31.47 \\
\hline 117.1 & & 36.69 \\
\hline 126.7 & & 42.34 \\
\hline 136.3 & & 48.81 \\
\hline 143.3 & & 54.79 \\
\hline 151.5 & & 62.22 \\
\hline 159.4 & & 70.67 \\
\hline 171(Congruent melting of $\mathrm{H} 3 \mathrm{BO} 3$ ) & & \\
\hline
\end{tabular}

The typical temperature of the operation condition is around $350 \mathrm{C} . \mathrm{H}_{3} \mathrm{BO}_{3}$ becomes transformed into $\mathrm{B}_{2} \mathrm{O}_{3}$ under this temperature. So the maximum solubility should be 92 weight percent of $\mathrm{B}_{2} \mathrm{O}_{3}$ (280000ppm Boron), which is very useful for boron holdup calculation if precipitation is considered.

Of interest is the potential of reactions and behavior of Lithium Metaborate because of the use of Lithium Hydroxide as a control of bulk coolant $\mathrm{pH}$. The solubility of Lithium Metaborate is shown in Fig. 14. Noticed there is a peak value on the curve. After the peak value, the solubility of $\mathrm{LiBO}_{3}$ goes down when temperature goes up, which is an important phenomenon for our model as the higher temperature would tend to lead to increased possibility of precipitation near the base of the crud layer where the highest temperatures occur. 


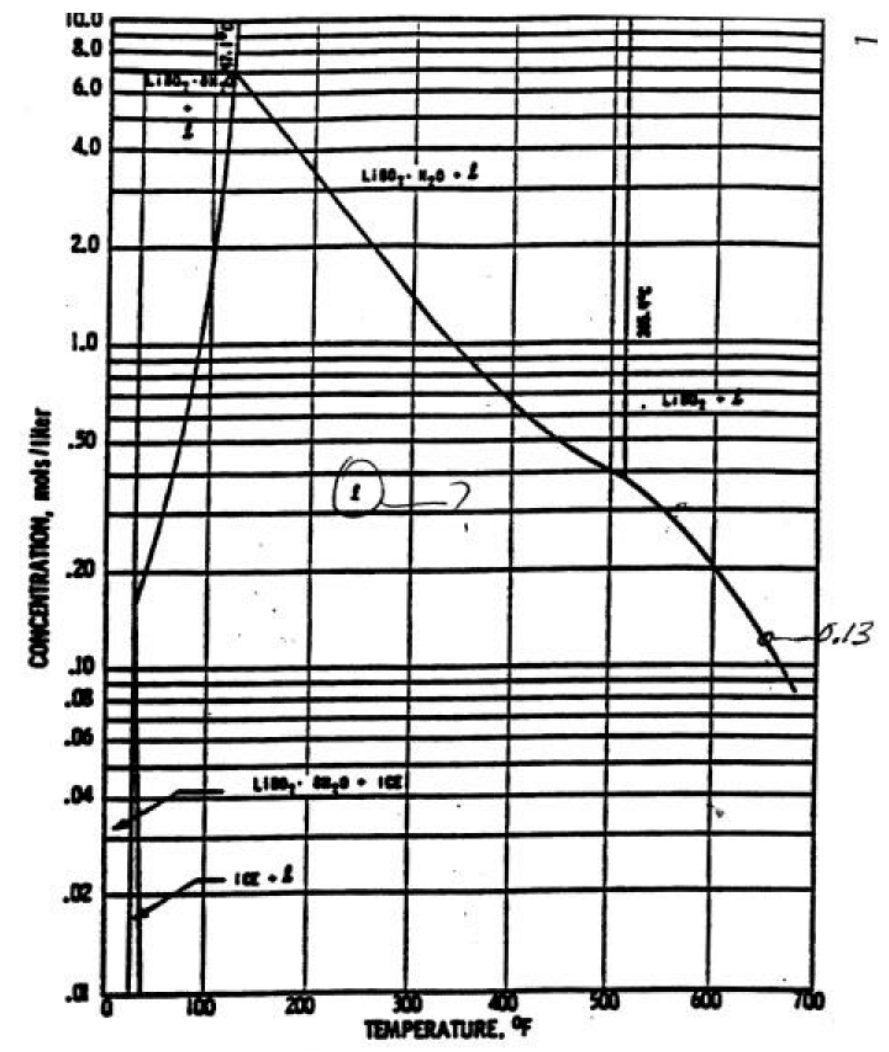

Fig. 14. The Solubility of Lithium Metaborate as a Function of Temperature[2]

\section{A-c) Idea of two layer model}

After the reactor shutdown, the fuel assemblies were checked and more corrosion was found at the bottom of the crud layer. This was mainly constituted of $\mathrm{ZrO}_{3}$, which contributes a decreased porosity in the lower layer of the crud. To incorporate this phenomenon in the analysis, a two-layer model has been developed.

Firstly, in order to assess the general behavior a less demanding one-dimensional, two-layer model has been considered. Following the earlier model nomenclature, this model is presented here. Consider the upper layer has 0.6 porosity and the lower layer has 0.3 porosity as shown in the following sketch.

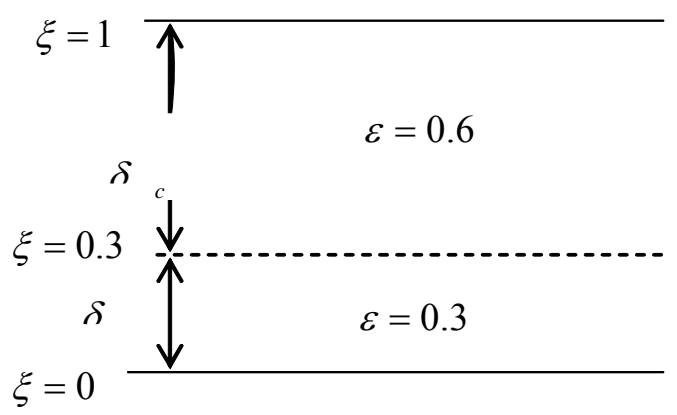


Governing Equations for the solute concentrations are:

$$
\begin{aligned}
& \frac{d^{2} C_{c}}{d^{2} \xi}-\frac{P e m_{1}}{A_{r 1}} \frac{d}{d \xi}\left[v_{l}(\xi) C_{c}\right]=0 \\
& \frac{d^{2} C_{o}}{d^{2} \xi}-\frac{P e m_{2}}{A_{r 2}} \frac{d}{d \xi}\left[v_{l}(\xi) C_{o}\right]=0
\end{aligned}
$$

Upper Layer $0.3<\xi<1.0$ Lower Layer $0.0<\xi<0.3$

where:

$$
\begin{aligned}
& \text { Pem }=\frac{U_{l} r_{v}}{D} \quad D=\tau \varepsilon D_{l} \\
& A r_{c}=\frac{r_{v}}{\delta_{c}} \quad A r_{o}=\frac{r_{v}}{\delta_{o}} \\
& V_{l}(\xi)=\frac{(-2)}{A_{r}\left(H^{2}-1\right)} \sum_{n=1}^{\infty} C_{n}\left[\frac{K_{1}\left(\gamma_{n} H\right)}{I_{1}\left(\gamma_{n} H\right)} I_{1}\left(\gamma_{n}\right)-K_{1}\left(\gamma_{n}\right)\right] \sin \left(\frac{\gamma_{n}}{A_{r}} \xi\right)
\end{aligned}
$$

$\mathrm{H}=$ ratio of outside radius of the unit cell to chimney radius.

Boundary Conditions:

1) $C_{c}(\xi=1)=1$

2) $C_{o}(\xi=0.3)=C_{c}(\xi=0.3)$

3) $\frac{1}{\varepsilon_{o}} \frac{d C_{c}(\xi=0.3)}{d \xi}=\frac{1}{\varepsilon_{c}} \frac{d C_{o}(\xi=0.3)}{d \xi}$

4) $\frac{d C_{c}(\xi=0)}{d \xi}=0$

The analytical solution is obtained and the plots for solute concentrations in the upper and lower layers, $C_{c}(\xi)$ and $C_{o}(\xi)$, are shown in Fig. 15. 


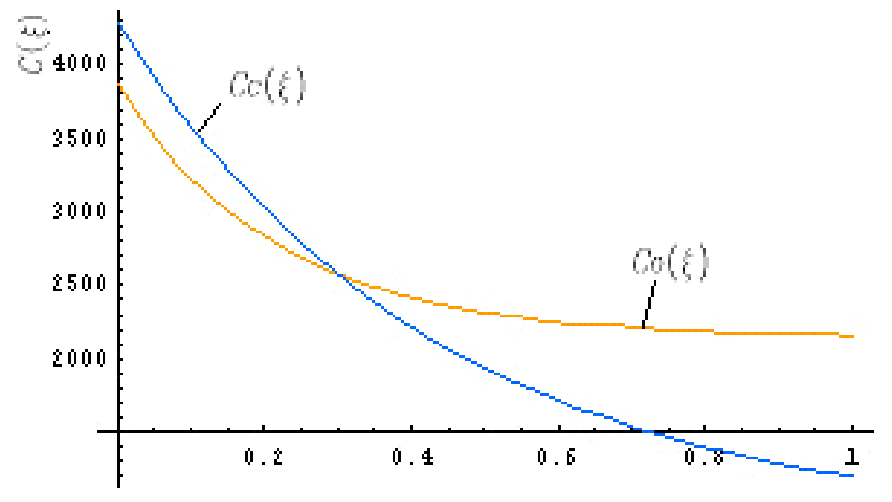

Fig. 15. Concentration distribution in the crud (Two Layers Model)

Next step could be to build the two-dimensional model, but the detail of coupling the two regions and fully modifying the code was postponed in favor of evaluating the precipitation potential and influence in the second year work.

\section{A-d) Future work}

1. Build two-dimensional two layers model with boiling adjacent to the bottom of the crud. Develop the governing equations and boundary conditions coupled with energy and momentum equations. Embed it into the code and get the plots for the result.

2. Develop relations for estimating the rate of other radiolysis products accumulation in the bubble. 
PHASES II AND III

A-a-II) Precipitation of boron compounds is incorporated into the porous layer computational model and change in performance of original model with newly acquired thermal-physical data is evaluated and predictions compared observed data. A-a-III) Comparison of newly modified code results with original predictions showing the effects of inclusion of additional phenomena.

1. Newly acquired thermal-physical data are listed below:

Referring again to Fig. 13 taken from Kracek et al.[ 6], which shows the $\mathrm{B}_{2} \mathrm{O}_{3}-\mathrm{H}_{2} \mathrm{O}$ system over the whole composition range, to the solubility data of $\mathrm{H}_{3} \mathrm{BO}_{3}$ in [7] and the following Table. 8 , an assessment of precipitation can be considered.

Table. 8. Solubility of $\mathrm{H}_{3} \mathrm{BO}_{3}$

\begin{tabular}{|c|c|c|}
\hline Temperature, $\mathrm{C}$ & & $\begin{array}{l}\text { Solubility } \\
\mathrm{g} \mathrm{H} 3 \mathrm{BO} / 100 \mathrm{~g} \text { of Solution in } \mathrm{H} 2 \mathrm{O}\end{array}$ \\
\hline & $\mathrm{P}=1 \mathrm{~atm}$ & \\
\hline 60 & & 12.97 \\
\hline 70 & & 15.75 \\
\hline 80 & & 19.06 \\
\hline 90 & & 23.27 \\
\hline 100 & & 27.53 \\
\hline & $\mathrm{P}=\mathrm{P}$ sat & \\
\hline 107.8 & & 31.47 \\
\hline 117.1 & & 36.69 \\
\hline 126.7 & & 42.34 \\
\hline 136.3 & & 48.81 \\
\hline 143.3 & & 54.79 \\
\hline 151.5 & & 62.22 \\
\hline 159.4 & & 70.67 \\
\hline 171(Congruent melting of $\mathrm{H} 3 \mathrm{BO} 3$ ) & & \\
\hline
\end{tabular}

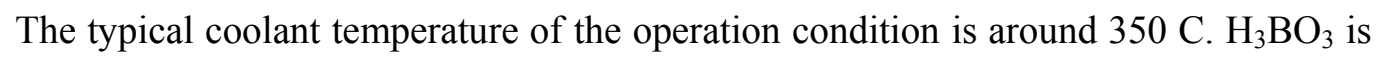
transformed into $\mathrm{B}_{2} \mathrm{O}_{3}$ under this temperature. So the maximum solubility should be 92 weight percent of $\mathrm{B}_{2} \mathrm{O}_{3}$ (280000ppm Boron), which is very useful for boron holdup calculations if precipitation is considered.

2. Incorporation of precipitation into the computational model.

As discussed above, Boron precipitates as solid $\mathrm{H}_{3} \mathrm{BO}_{3}$. Based on the assumption that all the boron precipitated fills the local pores in the crud, the boron holdup in the core is evaluated and compared with the results with no precipitation. Table. 9, Table. 10 , and Table. 11 show the results of these calculation (calculation process is shown in reference [8]). 
Table. 9. Callaway Cycle 9 8000MWD/MTU

\begin{tabular}{|c|c|c|}
\hline $\begin{array}{l}\text { Crud Thickness } \\
\text { (um) }\end{array}$ & $\begin{array}{c}\text { Boron Holdup (total) } \\
\text { (No precipitation considered) } \\
(\mathrm{kg})\end{array}$ & $\begin{array}{l}\text { Boron Holdup (total) } \\
\text { (Precipitation considered) } \\
\text { (kg) }\end{array}$ \\
\hline 85 & 0.06494 & 0.13728 \\
\hline 90 & 0.126 & 0.3006 \\
\hline 100 & 0.4632 & 0.82248 \\
\hline 105 & 0.895 & 1.41601 \\
\hline 110 & 1.746 & 2.99644 \\
\hline
\end{tabular}

Table. 10. Callaway Cycle 9 4000MWD/MTU

\begin{tabular}{|c|c|c|}
\hline $\begin{array}{l}\text { Crud Thickness } \\
\text { (um) }\end{array}$ & $\begin{array}{c}\text { Boron Holdup (total) } \\
\text { (No precipitation considered) } \\
(\mathrm{kg})\end{array}$ & $\begin{array}{l}\text { Boron Holdup (total) } \\
\text { (Precipitation considered) } \\
(\mathrm{kg})\end{array}$ \\
\hline 25 & 0.000105 & 0.0000105 \\
\hline 50 & 0.00495 & 0.00495 \\
\hline 75 & 0.267 & 0.267 \\
\hline 85 & 1.334 & 2.895 \\
\hline
\end{tabular}

Table. 11. Callaway Cycle 6 6000MWD/MTU

\begin{tabular}{|c|c|c|}
\hline $\begin{array}{l}\text { Crud Thickness } \\
\text { (um) }\end{array}$ & $\begin{array}{c}\text { Boron Holdup (total) } \\
\text { (No precipitation considered) } \\
(\mathrm{kg})\end{array}$ & $\begin{array}{l}\text { Boron Holdup (total) } \\
\text { (Precipitation considered) } \\
(\mathrm{kg})\end{array}$ \\
\hline 25 & $9.42 \mathrm{E}-5$ & $9.42 \mathrm{E}-5$ \\
\hline 50 & 0.03924 & 0.03924 \\
\hline 75 & 0.1829 & 0.1829 \\
\hline 85 & 0.8633 & 1.895 \\
\hline
\end{tabular}

From Table. 9, Table. 10, and Table. 11, it is concluded that precipitation occurs when the crud thickness accumulates to more than $85 \mathrm{um}$ and that precipitation increases the boron holdup in the core. It is noted that this result does not consider the influence of the precipitation filled porous volume in the lower region of the crud layer, which would influence heat transfer from the clad and increase the temperature drop across the crud layer.

\section{A-b) modify computational model to incorporate boiling in the region adjacent to the heating surface instead of only on the chimney walls as considered in the original model.}

The original model [9] showed that the imposed heat flux, $q_{o}^{\prime \prime}$, is primarily removed by latent energy transport at the chimney wall with only a small fraction conducting through the porous layer to the bulk coolant. When the heat flux is not high, boiling 
does not occur in the porous media and cooling is by conduction through the porous media. For dealing with relatively high heat flux, boiling in the region adjacent to the heating surface needs to be consideration. As a result, there can be a vapor layer at the bottom of the crud (Fig. 16). Under equilibrium conditions the energy balance determines the thickness and interfacial contour of this vapor layer. As a first approximation, the thickness of the vapor layer is set as a fixed thickness. Hence, the vapor layer can be taken as an extension of the chimney.

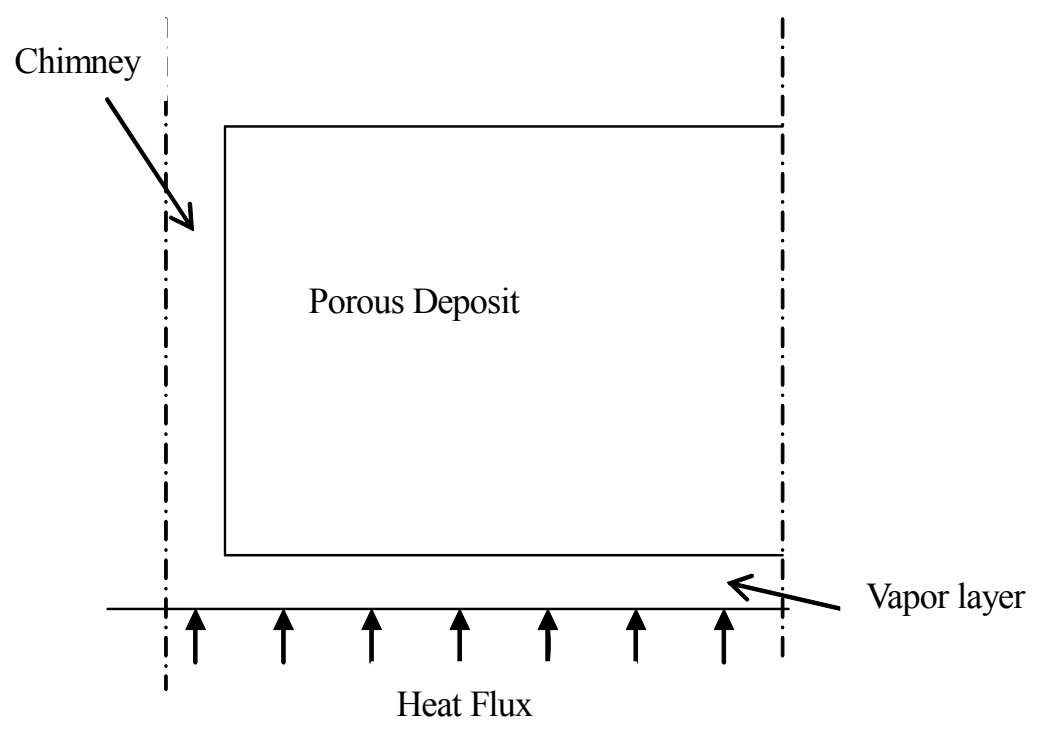

Fig. 16. The porous shell with vapor layer

The governing equations of energy, momentum and diffusion are generally the same as those used in the original model. But the boundary condition for the heating surface is changed. Details shows are presented below for the two-dimensional, cylindrical cell model:

Governing Equations:

1. Darcy's equation (equation of motion)

$$
\begin{array}{ll}
\text { r-direction } & \frac{\partial P_{l}}{\partial \eta}=\frac{1}{\operatorname{Re}_{m}} u_{l} \\
\text { z-direction } & \frac{\partial P_{l}}{\partial \xi}=\frac{1}{A_{r} \operatorname{Re}_{m}} v_{l}
\end{array}
$$

\section{Continuity equation:}

$$
\frac{1}{\eta} \frac{\partial}{\partial \eta}\left(\eta u_{l}^{*}\right)+A_{r} \frac{\partial}{\partial \xi} v_{l}^{*}=0
$$


where:

$$
\begin{aligned}
& P_{l}^{*}=\frac{P_{s}-P_{l}}{\rho_{l} U_{l}^{2}} ;\left(u_{l}^{*}, v_{l}^{*}\right)=\frac{1}{U_{l}}\left(u_{l}, v_{l}\right) \\
& \eta=\frac{r}{r_{v}} ; \xi=\frac{z}{\delta} ; A_{r}=\frac{r_{v}}{\delta} \\
& \operatorname{Re}_{m}=\text { Modified Reynolds number in the porous shell }=\frac{U_{l} \kappa}{v_{l} r_{v}}
\end{aligned}
$$

Boundary Conditions for the equations of motion:

At Chimney wall: $u_{l}\left(r=r_{v}\right)=(-1) \frac{j(z)}{\rho_{l}}$

At vapor layer: $v_{l}\left(z=z_{v}\right)=(-1) \frac{j(r)}{\rho_{l}}$

At cell boundary: $\left(\frac{\partial P_{l}}{\partial \eta}\right)_{\eta=H}=0 \quad$ (symmetry boundary)

\section{Energy Equation:}

$$
\nabla^{2} \theta=0
$$

where: $\theta=\frac{T-T_{r}}{\Delta T_{w}}$

\section{Solute Transport Equation:}

$$
\nabla^{2} \phi=P e_{m}\left[\frac{1}{\eta} \frac{\partial}{\partial \eta}\left(\eta u_{l}^{*} \phi\right)+A_{r} \frac{\partial}{\partial \xi}\left(v_{l}^{*} \phi\right)\right],
$$

where: $\phi=$ local concentration factor $=\frac{C}{C_{b}}$

$$
\begin{aligned}
& C_{b}=\text { Solute concentration in the bulk fluid, and } \\
& P e_{m}=\text { Peclet Number based on the chimney radius }=\frac{U_{l} r_{v}}{D}
\end{aligned}
$$

Boundary conditions for Energy equation:

At the chimney wall: $\left(\frac{\partial \theta}{\partial \eta}\right)_{\eta=1}=\frac{H_{f g} r_{v}}{K_{m} \Delta T_{w}} j(\xi) \quad$ (continuity of heat flux) 
At the vapor layer: $\left(\frac{\partial \theta}{\partial \xi}\right)_{\eta=1}=\frac{H_{f g} r_{v}}{K_{m} \Delta T_{w}} j(\eta)$

In the vapor layer: $U_{l}=\frac{q_{0}^{\prime \prime} / f}{H_{f g} \rho_{l}} \quad($ refer to reference [10])

At the cell boundary: $\left(\frac{\partial \theta}{\partial \eta}\right)_{\eta=H}=0 \quad$ (symmetry boundary)

Along the heating surface, a constant heat flux is imposed such that,

$$
-K_{m}\left(\frac{\partial T}{\partial z}\right)_{z=0}=q^{\prime \prime}
$$

The effective thermal conductivity of isotropic porous deposit $\mathrm{Km}$ is determined as [11],

$$
K_{m}=K_{l} \frac{1-\left(1-a K_{p} / K_{l}\right) b}{1+(a-1) b}
$$

where:

$$
\begin{aligned}
& K_{l}=\text { thermal conductivity of continuous phase } \\
& K_{p}=\text { thermal conductivity of particulate phase } \\
& \begin{array}{l}
a=\frac{3 K_{l}}{2 K_{l}+K_{p}} \\
b=1-\varepsilon
\end{array}
\end{aligned}
$$

Using the above equations and boundary conditions, the original model is modified and embedded into the Fortran code. Fig. 17 shows the numerical result of this first approximation, where vapor layer thickness is set equal to the chimney radius, which is $2.5 \mathrm{um}$.

Comparing this result with that of the original model (Fig. 18), it is concluded that the temperature difference in the crud increases which means that the vapor layer decreases the heat transfer ability of the crud. Thus, with an increase of thickness of the vapor layer, the heat transfer performance of the crud decreases. The existence of the vapor layer also changes the flow direction in the crud layer and causes a speed up the flow velocity, which results in more solute accumulation in the crud as shown in Fig. 17. This result is very important to the study of axial offset anomaly in the PWRs. It ties in with the study of electrolysis products distribution in porous layers reported in a later section of this report. 

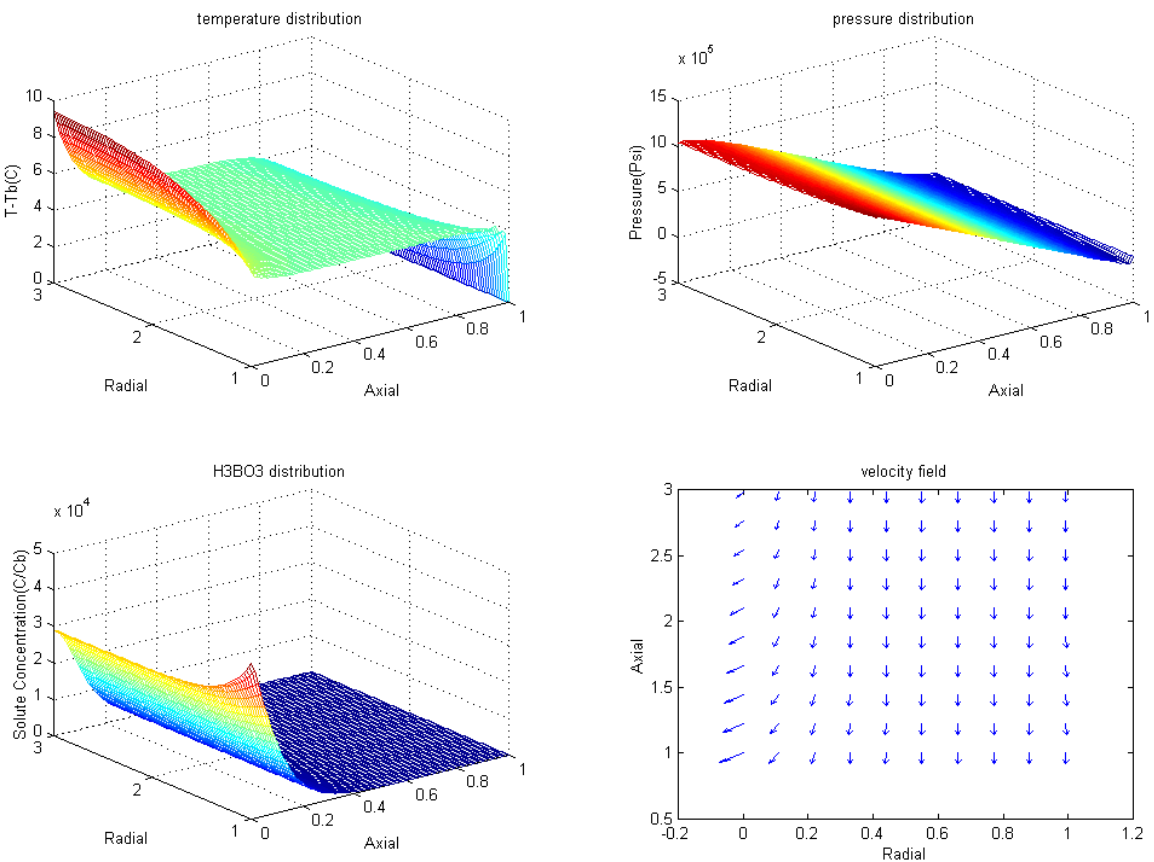

Fig. 17. Numerical Result (with vapor layer)

$\mathrm{Nv}=6000, \mathrm{rv}=2.5, \delta=50 \mathrm{um}, \mathrm{P}=2279 \mathrm{psi}, \quad \delta_{v}=2.5$
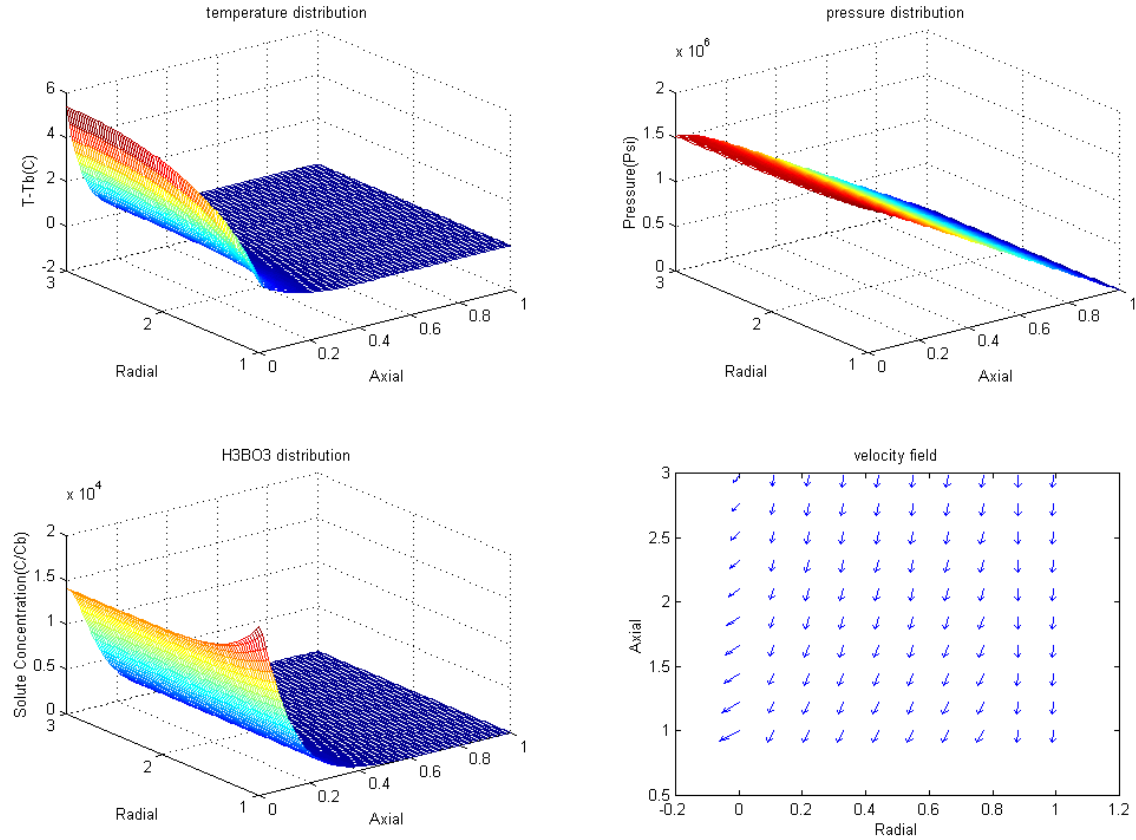

Fig. 18. Numerical Result (without vapor layer) $\mathrm{Nv}=6000, \mathrm{rv}=2.5, \delta=50 \mathrm{um}, \mathrm{P}=2279 \mathrm{psi}$ 
PART B - DETERMINATION OF THE INFLUENCE OF BUBBLES ATTACHED TO FUEL PIN SURFACES IN SUB-COOLED BOILING ON CREATING THE NECESSARY ENVIRONMENT FOR CRUD DEPOSITION

\section{PHASES I AND II}

\section{B-a): New model introduced for evaluation of concentration of soluble components at bubble/wall/liquid interface.}

The model is introduced below and results are evaluated and presented.. Figure 20 provides a visual display highlighting the essential aspects of the configuration and model.

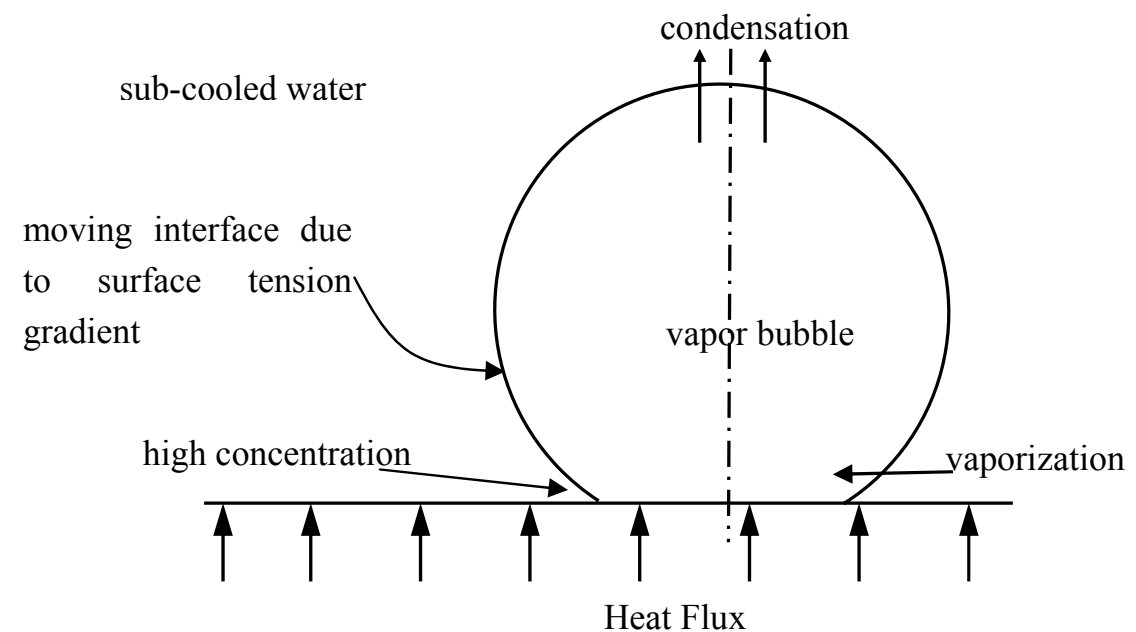

Fig. 19. Schematic description of spherical vapor bubble

The hemispherical vapor bubble model of an earlier study is modified to incorporate the spherical shape of the bubble. Fig. 19 demonstrates the physical process around the spherical vapor bubble attached to the solid heating surface. The surface tension driven flow, due to the temperature difference along the bubble interface, evaporates the solution at the base of bubble and condenses the vapor at the top of bubble. Therefore, there is a high concentration region near the base of bubble. Higher concentration at that region is expected when a spherical bubble model is applied. Fig. 20 shows the geometry of the spherical bubble. Since the bubble is symmetric, half of it is considered.

Governing Equations:

The following set of non-dimensional variables is introduced:

$$
r^{*}=r / R ; t^{*}=\alpha_{L} t / R^{2} ; \vec{v}^{*}=\vec{v} R / \alpha_{L} ; p_{d}^{*}=p_{d} R^{2} /\left(\rho_{L} \alpha_{L}^{2}\right)
$$




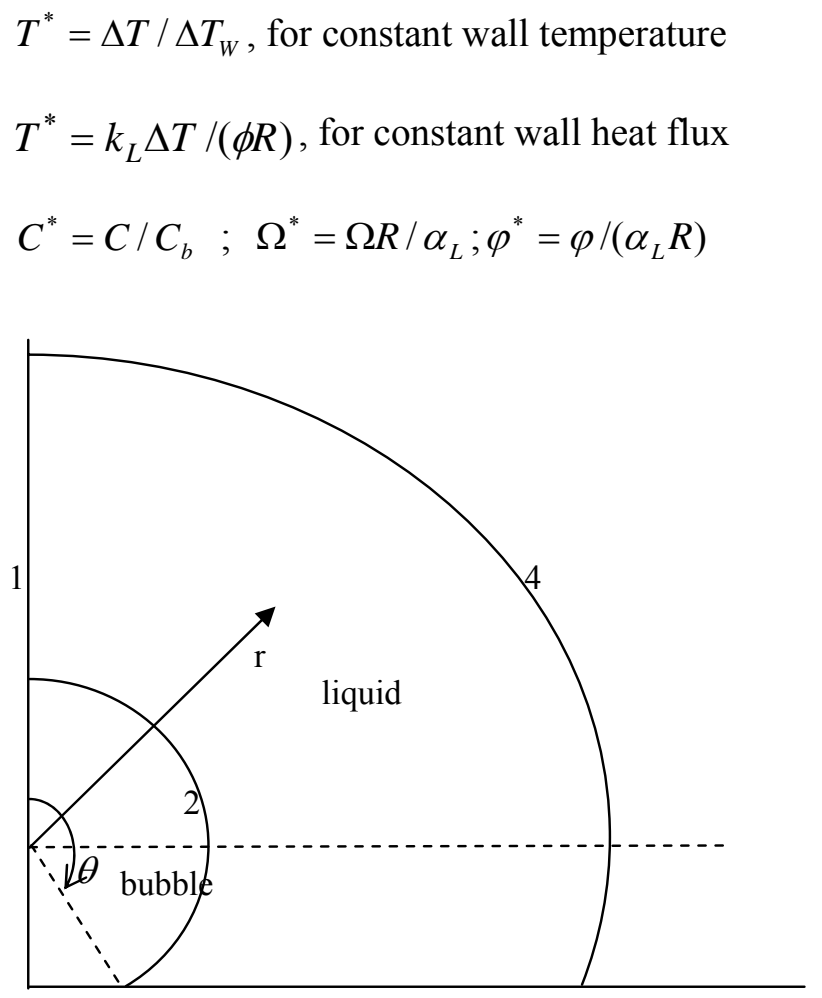

Fig. 20. The Problem Geometry of Spherical Bubble Model

The vorticity equation and the associated Poisson type of stream-function equation have been adopted to represent the momentum equation. The conservation equations can be written as follows:

$$
\begin{gathered}
\frac{\partial\left(\Omega^{*}\right)}{\partial t^{*}}+\frac{\partial\left(\Omega^{*} u^{*}\right)}{\partial r^{*}}+\frac{1}{r^{*}} \frac{\partial\left(\Omega^{*} v^{*}\right)}{\partial \theta^{*}}=\operatorname{Pr}\left[\frac{\partial^{2} \Omega^{*}}{\partial r^{* 2}}+\frac{1}{r^{* 2}}\left(\frac{\partial^{2} \Omega^{*}}{\partial \theta^{* 2}}+\cot \theta \frac{\partial \Omega^{*}}{\partial \theta}-\frac{\Omega^{*}}{\sin ^{2} \theta}\right)\right] \\
+\delta r^{*}\left(\sin \theta \frac{\partial T^{*}}{\partial r^{*}}+\frac{\cos \theta}{r^{*}} \frac{\partial T^{*}}{\partial \theta^{*}}\right) \\
-\Omega^{*} \sin \theta=\frac{\partial^{2} \varphi^{*}}{\partial r^{* 2}}+\frac{1}{r^{* 2}}\left(\frac{\partial^{2} \varphi^{*}}{\partial \theta^{2}}-\cot \theta \frac{\partial \varphi^{*}}{\partial \theta}\right)
\end{gathered}
$$

and the energy equation:

$$
\frac{\partial T^{*}}{\partial t^{*}}+u^{*} \frac{\partial T^{*}}{\partial r^{*}}+\frac{v^{*}}{r^{*}} \frac{\partial T^{*}}{\partial \theta}=\frac{\partial^{2} T^{*}}{\partial r^{* 2}}+\frac{2}{r^{*}} \frac{\partial T^{*}}{\partial r^{*}}+\frac{1}{r^{* 2}}\left(\frac{\partial^{2} T^{*}}{\partial \theta^{2}}+\cot \theta \frac{\partial T^{*}}{\partial \theta}\right)
$$

and the concentration equation:

$$
\frac{\partial C^{*}}{\partial t^{*}}+u^{*} \frac{\partial C^{*}}{\partial r^{*}}+\frac{v^{*}}{r^{*}} \frac{\partial C^{*}}{\partial \theta}=L e\left[\frac{\partial^{2} C^{*}}{\partial r^{* 2}}+\frac{2}{r^{*}} \frac{\partial C^{*}}{\partial r^{*}}+\frac{1}{r^{* 2}}\left(\frac{\partial^{2} C^{*}}{\partial \theta^{2}}+\cot \theta \frac{\partial C^{*}}{\partial \theta}\right)\right]
$$


with $\varphi^{*}$ being defined as:

$$
u^{*}=\frac{1}{r^{* 2} \sin \theta} \frac{\partial \varphi^{*}}{\partial \theta} \text { and } v^{*}=\frac{1}{r^{*} \sin \theta} \frac{\partial \varphi^{*}}{\partial r^{*}}
$$

Considering the non-dimensionalization introduced above, the boundary conditions can be written as, referring to Fig. 19:

BC 1: at symmetry line: $\frac{\partial u}{\partial \theta}=0, v=0, \Omega=0$,

$$
\varphi=0, \frac{\partial T}{\partial \theta}=0, \frac{\partial C}{\partial \theta}=0
$$

BC 3: at wall: $\quad u=v=0$ (no slip), $\Omega=-\frac{1}{r^{2}} \frac{\partial^{2} \varphi}{\partial \theta^{2}}, \varphi=0$,

$$
\begin{aligned}
& T=1(\text { constant wall temperature), } \\
& \frac{1}{r} \frac{\partial T}{\partial \theta}=1 \quad \text { (constant wall heat flux), }
\end{aligned}
$$

The solute flux vanishes at the wall, as it is assumed that there are no reactions between the heating surface and the solute. Thus,

$\mathrm{BC}$ 2: at bubble interface:

$$
\frac{\partial C}{\partial \theta}=0
$$

$$
\begin{gathered}
\frac{\partial T(1, \theta)}{\partial r}=B i\left[T(1, \theta)-T_{v}\right] \\
T_{v}=\int_{0}^{\pi / 2} T(1, \theta) \sin \theta d \theta \\
u(1, \theta)=\operatorname{Bi} \varepsilon\left[T_{v}-T(1, \theta)\right] \\
\varphi(1, \theta)=\int_{0}^{\theta} u(1, \theta) \sin \theta d \theta \\
\Omega(1, \theta)=(M a+2 B i \varepsilon) \frac{\partial T(1, \theta)}{\partial \theta}+2 v(1, \theta)
\end{gathered}
$$

At the bubble interface, the radial flux vanishes given that the solute is non-volatile. This result in:

$$
j_{s r}=-D_{j} \frac{\partial C}{\partial r}+u C=0 \quad \text { (dimensional form) }
$$

so that:

$$
\begin{aligned}
& -L e \frac{\partial C}{\partial r}+u C=0 \quad \text { (non-dimension form) } \\
& C(1, \theta)=\frac{L e}{u(1, \theta)} \frac{\partial C(1, \theta)}{\partial r}
\end{aligned}
$$

BC 4: at infinity:

$$
u=v=\Omega=\varphi=T=0, \text { and } C=1
$$


The initial state of the system was assumed to be such that, at $t=0$

$$
u=v=\Omega=\varphi=T=0
$$

all the solute concentration is uniform and equal to bulk concentration. Thus,

$$
C_{t=0}=1
$$

The difference between hemispherical and spherical bubble models is the numerical method required to handle the wall boundary. An original structured grid cannot handle this kind of boundary. An unstructured grid method needs to be employed. The numerical simulation with this method is under development. It is expected that the maximum concentration calculated with the spherical model will be higher than that of the hemispherical one, since the underside of a spherical bubble tends to trap some static liquid and the diffusion of the concentration will not be as strong as a hemispherical one. Therefore, this will create the environment to initiate the deposition.

\section{B-b) Documentation of models for rate of accumulation of crud products and stripping of the gaseous products from radiolysis of water.}

Research has been done on crud formation and its effects on the reliability of fuel element operation and on crud induced axial power shift. Causes of crud formation have been reviewed considering the effects of corrosion, heat flux, and radiation on zircaloy fuel cladding at high burnups. Corrosion of zircaloy cladding and crud initiation under LWRs operating conditions are very complex processes that depend on many factors, including electrochemistry (oxidation- reduction) reactions, temperature, radiation, and water chemistry in the primary coolant.

It is observed that almost all types of corrosion can be explained in terms of oxidation-reduction reactions. The corrosion of zircaloy for two different stages, pre-transition and post-transition, is reviewed. The post-transition stage is considered the most important because of influences on the reliability of fuel element operation and crud induced axial power shift. When the oxygen concentration in the film fulfills stoichiometry, the zirconium oxide is no longer a passive layer that protects the zircaloy clad and it grows as a white porous layer, which can be described by a wick boiling and diffusion model.

Corrosion by heat flux and radiation effects is a function of a number of factors such as fast neutron fluence, oxygen concentration in the coolant, absolute temperature at the coolant and cladding interface, the condition of the alloy surface, and the metallurgical state of the crud layer. The lower thermal conductivity in the zirconium oxide causes an increase in temperature of the metal-oxide interface, which increases the potential of anode and cathode to corrode the metal surface. Radiolysis produced $\mathrm{H}_{2} \mathrm{O}_{2}$, which has the longest life-time of radiolysis products and has a large ionization 
trail, provides the largest contribution to the corrosion process. Corrosion weight gains and oxide film observations show that the average surface roughness is larger on gamma-ray irradiated surfaces than on the non-irradiated surfaces. This increases the nucleation site density and contributes to enhanced corrosion on the zircaloy cladding.

The two kinds of mass-transfer mechanisms that contribute to the behavior of the coolant in porous zirconium oxide layer deposits are molecular diffusion and mass convection. Specifically, the transport of the radiolysis products, molecular hydrogen $\left(\mathrm{H}_{2}\right)$ and oxygen $\left(\mathrm{O}_{2}\right)$, have been investigated, and it is shown that molecular diffusion dominates mass convection in the porous crud layer.

The concentration distribution of $\mathrm{H}_{2}$ shows that the $\mathrm{H}_{2}$ exists predominantly in the upper portion, $\sim$ upper $10 \%$ (Fig. 21 ), of the porous region. There is a rapid decrease of $\mathrm{H}_{2}$ concentration with depth from the crud-bulk coolant interface. The concentration distribution of $\mathrm{O}_{2}$, however, shows the opposite behavior to that of $\mathrm{H}_{2}$, as most of the $\mathrm{O}_{2}$ exists in the lower portion, which is is in the lower 90\% (Fig. 22) of the porous region, with rapid increase of concentration with depth from the crud-bulk coolant interface. This distribution of radiolysis products supports the oxidation-reduction reaction at the post-transition stage, where more $\mathrm{O}_{2}$ is consumed at the interface between metal clad and crud oxide layer and more $\mathrm{H}_{2}$ exists at the interface between bulk coolant and crud oxide layer. 


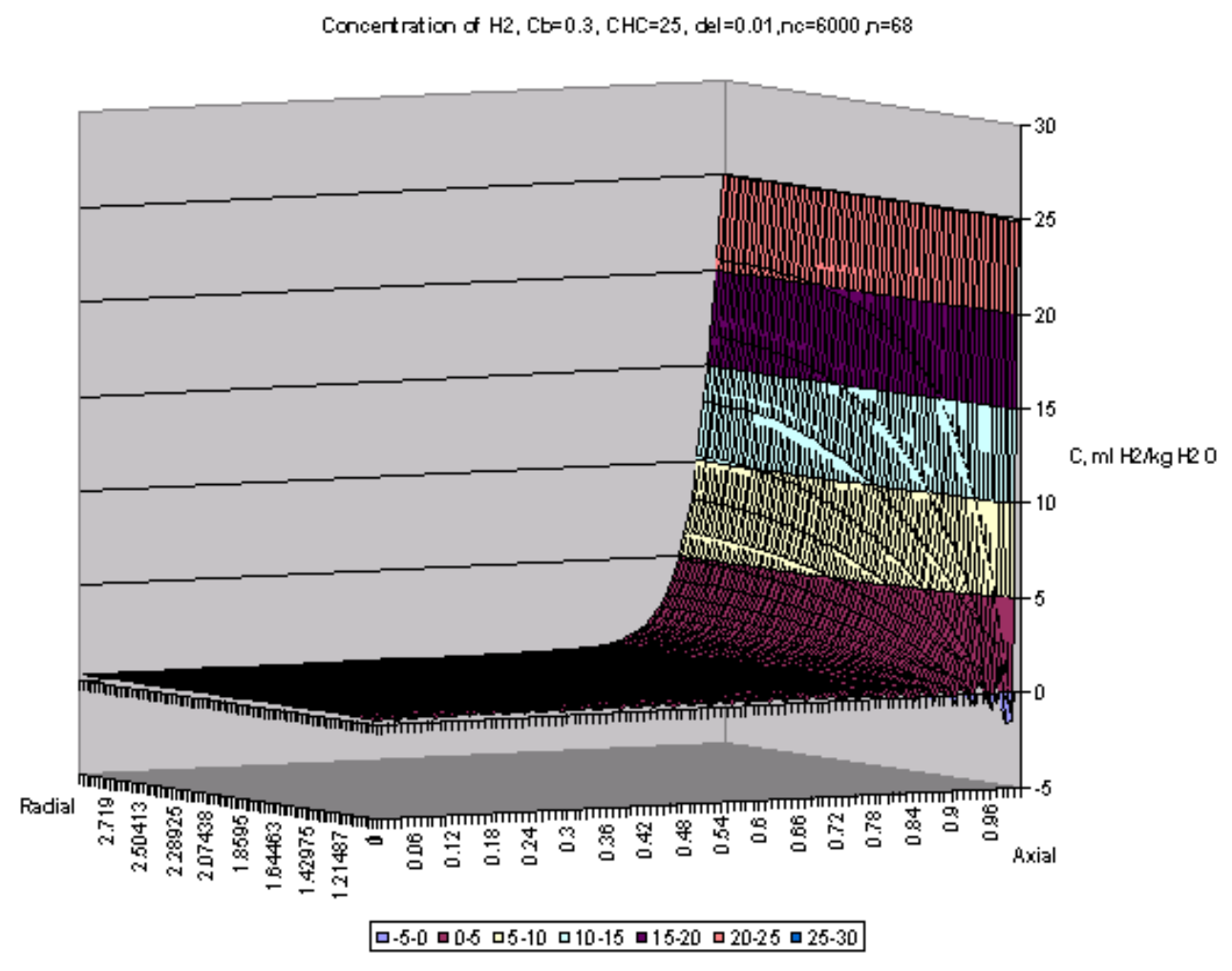

Fig. 21. Concentration distribution of $\mathrm{H}_{2}$ with $\delta=100 \mu \mathrm{m}^{3}$

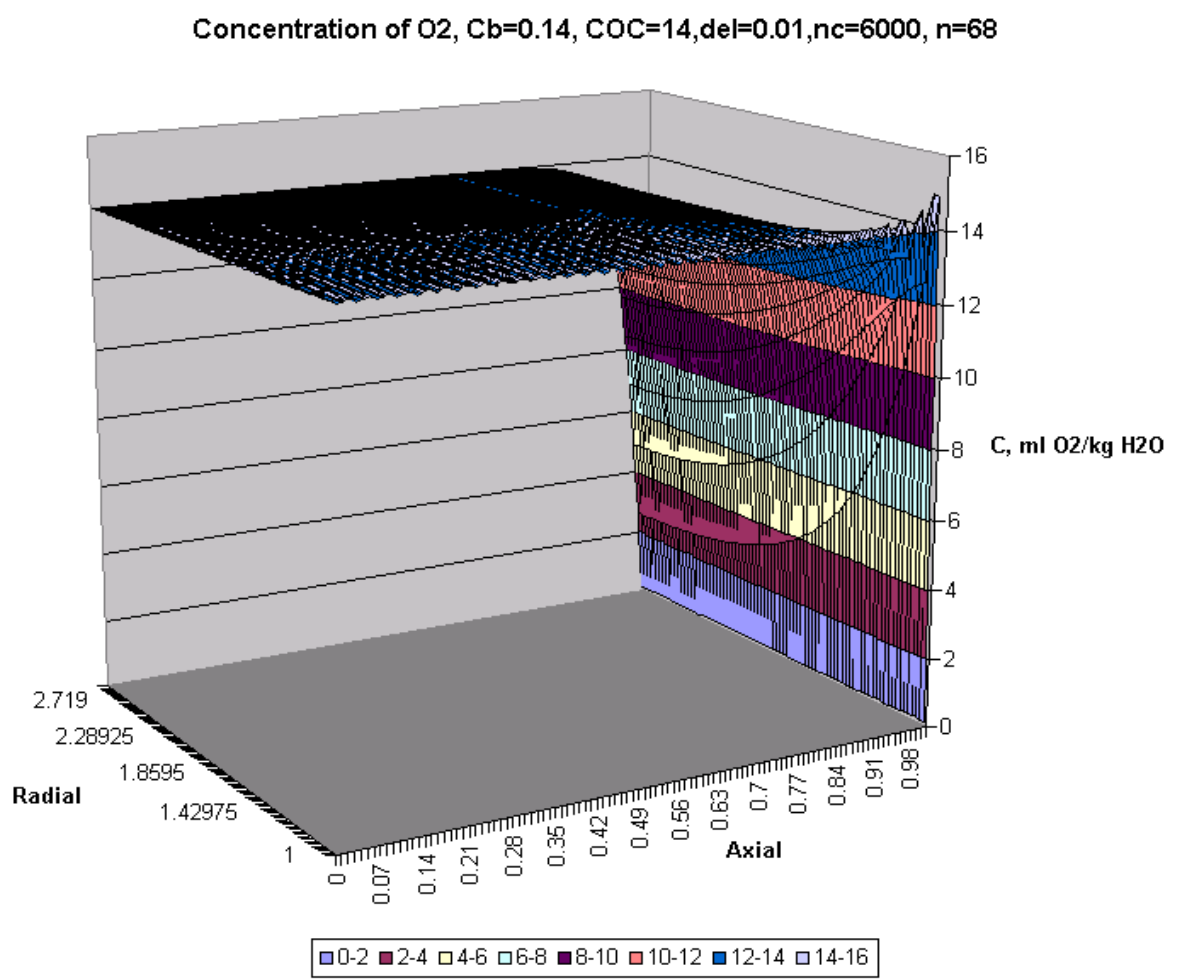

Fig. 22. Concentration distribution of $\mathrm{O} 2$ with $\delta=100 \mu \mathrm{m} 3$ 


\section{PHASE III}

\section{B-a) Evaluation of rate of crud deposition and radiolysis product striping by bubbles and radiation field}

\section{INTRODUCTION}

The occurrence of axial offset anomaly (AOA) is related to the deposition rate of corrosion products and the concentration of boron in the deposit layer (crud) on the fuel cladding. Deposition and precipitation of boron on the fuel cladding during boiling of water containing boron in PWRs can depress the local neutron flux and lead to a local decrease in nuclear reactor power. The purpose of the present work is to examine boron concentration fields, due to surface tension driven flow, around a bubble undergoing sub-cooled boiling in the vicinity of the cladding of a fuel rod. When the concentration of boron is higher than the solubility limit, boron is expected to precipitate from the solution and attach to the heated surface.

Surface tension on bubble interfaces is a function of temperature and concentration. When a surface tension gradient is established along a liquid-gas interface, motion is induced by a shear stress unbalance promoted on the interface. Such motion is generally named Marangoni flow [17]. The interface of a bubble seated on a heated wall and surrounded by liquid is subjected to a temperature gradient, which induces a liquid flow in the form of a jet of warm liquid streaming from the bubble apex, normal to the heater surface. Mass transferred across the vapor bubble interface also leads to variations of local solute concentrations around bubbles. The difficulties of making physically reliable observations of surface tension driven flows, under normal nucleate boiling conditions, led to the analysis of an alternate problem. The idea was to produce a stable bubble on a heated wall. Larkin [18] presented numerical time-dependent solutions for a hemispherical adiabatic bubble in pure water. Kao and Kenning [19] presented steady state solution for an adiabatic hemispherical bubble, but for a limited range of parameters. Jabardo [20] studied transient numerical solutions for adiabatic and diabatic hemispherical bubbles for a wide range of parameters. Recently, Rao and Jones [21] studied surface tension driven flow around a hemispherical vapor bubble in a binary mixture and found that the maximum solute concentration is about $25 \%$ higher than the bulk concentration for $\mathrm{LiOH}$ solution.

In the previous studies, the bubble was considered as hemispherical, which greatly simplifies the wall boundary conditions and domain discretization in spherical polar coordinates for numerical investigation. However, the bubble contact angle is fixed as $90^{\circ}$ in a hemispherical bubble, which is not true in most real situations.

In this study, the previously developed hemispherical bubble model will be extended to a full spherical bubble, which means the bubble contact angle can range from $0^{0}$ to $90^{\circ}$. The surface tension driven flow and boron concentration distributions around the 
bubble under sub-cooled boiling will be simulated with constant wall temperature. Some parameters, including bubble contact angle and sub-cooling level, will also be studied for their effects on boron concentration distribution. Boron precipitation under these circumstances will be discussed.

\section{MODEL DESCRIPTION}

Consider the motion around a bubble nucleus which has been placed on a wall and surrounded by boric acid solution. Due to the physical symmetry of the problem, half of the region is selected as the computational domain shown in Fig. 23. Initially the liquid's temperature and concentration distributions are uniform and evolve toward a new steady state condition. Before presenting the temporal conservation equations several assumptions must be made concerning the physical model sketched in Fig. 23:

1. Bubble's shape and volume are constant

2. Spherical symmetry, which results in a two-dimensional problem in spherical polar coordinates

3. Boussinesq assumptions are considered valid.

4. Heat conducted through the vapor in the bubble is negligible, which is equivalent to assuming zero vapor thermal conductivity

5. The vapor viscosity is considered negligible compared to that of the liquid

6. The surrounding liquid is considered infinite in extent

7. Gravity is negligible, which is a reasonable assumption for small bubbles.

8. There are no reactions between the heating surface and solute.

9. Constant wall temperature is applied

Note that the tangential coordinate $\theta$ starts from the symmetry line and goes in clockwise direction in Fig. 23.

The wall boundary conditions can be written as:

$$
\begin{gathered}
u=v=0 \text { (no slip), } \psi=0 \\
\Omega=\frac{1}{-\sin \theta}\left[\frac{\partial^{2} \psi}{\partial r^{2}}+\frac{1}{r^{2}}\left(\frac{\partial^{2} \psi}{\partial \theta^{2}}-\cot \theta \frac{\partial \psi}{\partial \theta}\right)\right] \\
T=1 \quad \text { (constant wall temperature) }
\end{gathered}
$$

The solute flux vanishes at the wall, as it is assumed that there are no reactions between the heating surface and the solute. Thus,

$$
-\frac{\partial C}{\partial r} \cos \theta+\frac{\partial C}{r \partial \theta} \sin \theta=0
$$

The initial state of the system was assumed:

$$
\text { At } \mathrm{t}=0, \quad u=v=\Omega=\psi=T=0
$$

The initial boron concentration is uniform and equal to the bulk concentration. Thus,

$$
C_{t=0}=1
$$


Several dimensionless parameters have been defined:

$\mathrm{Bi}=$ Biot Number $=\frac{h R}{k_{L}}$

$\varepsilon=$ Modified Jacob Number $=\frac{\Delta T_{W} c_{L}}{\lambda_{f g}}$

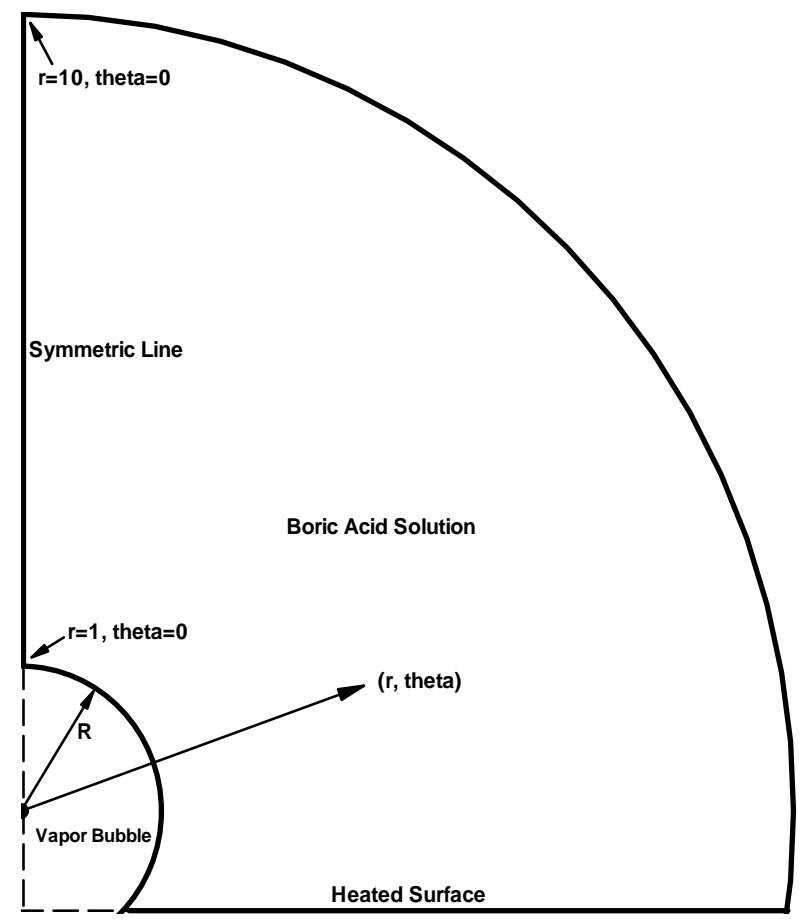

Fig. 23. Computation Domain of the Problem

$\mathrm{Ma}=$ Thermocapillary Marangoni Number $=\frac{(\partial \sigma / \partial T) \Delta T_{W} R}{\mu_{L} \alpha_{L}}$

Physically the Marangoni number can be interpreted as a modified Peclet number, with the inertial forces replaced by the capillary forces, arising from temperature gradients along the bubble interface.

$\operatorname{Pr}=$ Prandtl Number $=\frac{v}{\alpha_{L}}$

Le $=$ Lewis Number $=\frac{D_{j}}{\alpha_{L}}=\frac{\operatorname{Pr}}{S c}$

$\mathrm{Sc}=$ Schmidt Number $=\frac{v}{D_{j}}$

It's worth mentioning that in this model, surface tension is only considered as a function of temperature, which means that the effect of boron concentration gradients on surface tension is not modeled. For the first step to study the surface tension driven flow and concentration fields around spherical bubbles, this model is acceptable. For the next step, fully coupling the concentration equation and the momentum equation is needed to obtain better simulation of the phenomenon. 


\section{NUMERICAL TECHNIQUES}

An explicit scheme with finite difference method has been adopted for this transient problem. The computation domain was discretized in $\mathrm{r}$ and $\theta$ directions. An unstructured node-numbering method has been used in the study. This method simplifies the numerical process on boundary conditions. Discretization of the non-linear convective terms was successfully handled by combining first and second upwinding methods, depending on whether the equation is written in non-conservative or conservative form. 2046 nodes are used in the calculation. Doubling the number of nodes does not change the results.

\section{RESULTS AND DISCUSSIONS}

In this section the results obtained with the two-dimensional model are presented. The results for sample case are presented in Subsection 4.1. The parameters under study include bubble contact angle and sub-cooling level.

\subsection{Reference Case}

A reference case has been selected to evaluate the proposed model. It is defined by the conditions expected in PWRs at: i.e. $P_{s}=155 \mathrm{~atm}$, bubble contact angle $=55^{\circ}, \Delta T_{\mathrm{w}}=30^{\circ} \mathrm{C}$, $\mathrm{R}=10 \mu \mathrm{m}$. The initial boric acid concentration in bulk solution is taken to be $1800 \mathrm{ppm}$. The thermal and physical properties of boric acid solution are evaluated at the saturation conditions corresponding to $T_{\text {coolant }}=300^{\circ} \mathrm{C}$ as shown in Table. 12. The diffusivity coefficient of boron is $1.0 \times 10^{-8} \mathrm{~m}^{2} / \mathrm{s}$ [22]. The interfacial heat transfer coefficient of bubble is $2.7 \times 10^{7} \mathrm{~W} /\left(\mathrm{m}^{2} \cdot \mathrm{K}\right)$ [21]. In this case, the nondimensional parameters are calculated as: $\mathrm{Ma}=5600, \varepsilon=0.124, \operatorname{Pr}=0.97, B i=500$, and $S_{c}=12.7$. The following results are obtained when $t^{*}=0.1$ (real time is $0.07 \mathrm{~ms}$ )

Table. 12. Thermal and physical properties in the sample case

\begin{tabular}{|c|c|c|}
\hline$\rho_{L}$ & $\mathrm{~kg} / \mathrm{m}^{3}$ & $7.13 \times 10^{2}$ \\
\hline$k_{L}$ & $\mathrm{~W} /(\mathrm{m} \cdot \mathrm{K})$ & 0.541 \\
\hline$\mu_{L}$ & $\mathrm{~N} \cdot \mathrm{s} / \mathrm{m}^{2}$ & $9.07 \times 10^{-5}$ \\
\hline$c_{L}$ & $\mathrm{~J} /(\mathrm{kg} \cdot \mathrm{K})$ & $5.794 \times 10^{3}$ \\
\hline$\alpha_{L}$ & $\mathrm{~m}^{2} / \mathrm{s}$ & $1.37 \times 10^{-7}$ \\
\hline$-d \sigma / d T$ & $\mathrm{~N} /(\mathrm{m} \cdot \mathrm{K})$ & $2.3 \times 10^{-4}$ \\
\hline$\lambda_{f g}$ & $\mathrm{~J} / \mathrm{kg}$ & $1.404 \times 10^{6}$ \\
\hline
\end{tabular}

\subsubsection{Flow Field Distribution}

Under sub-cooled boiling, liquid is driven from the hot end of bubble to its cold end due to the moving bubble interface. Vortex is observed around the bubble (Fig. 24). 
The tangential velocity profile along bubble interface is shown on Fig. 25. The tangential velocity increases rapidly and reaches its maximum value near the heated wall and then gradually decreases to zero at the top of the bubble. At the lower portion of the bubble the radial velocity is toward the bubble, which means the liquid is vaporizing. While at the upper portion, the radial velocity is toward the surrounding liquid, which means the vapor is condensing to liquid (Fig. 26). But the radial velocity associated to the mass transfer across the interface is a magnitude smaller than the tangential velocity due to the temperature gradients.

\subsubsection{Boron Concentration Distribution}

Fig. 27 shows the boron concentration distribution around the bubble. Concentrated boron solution is found near the wall along the bubble interface. And the diluted boron solution is observed closer to the upper portion of the interface. These concentrating and diluting phenomena are due to the fact that water is undergoing phase change between liquid and vapor along the bubble interface, while boron is left in the liquid. The maximum boron concentration is 2.8 times of that in the bulk solution and it is located at the intersection of bubble interface and heated wall (Fig. 28).

\subsection{Effect of Bubble Contact Angle on the Maximum Boron Concentration}

In this calculation, physical conditions are the same as the above reference case. The effect of bubble contact angle on the maximum concentration factor is shown on Fig. 29. For a hemispherical bubble, contact angle $=90^{\circ}$, the maximum boron concentration factor is 1.94 . However, when the bubble contact angle is $15^{\circ}$, this factor goes up to 4.62. For smaller contact angle bubble, especially when the angle is less than $30^{\circ}$, a relatively large stagnation region is presented underneath the bubble, in which the liquid is trapped. This prevents the convection of liquid from taking the concentrated solute away from the bubble interface. Therefore, larger concentration occurs for smaller contact angle bubbles. If the maximum boron concentration exceeds the boron solubility, the boron will precipitate from the solution. Note that the concentration factor is 4.62 for $15^{\circ}$ contact angle bubble, but this concentration does not reach the boron solubility limit.

\subsection{Effect of Sub-Cooling Level on Surface Tension Driven Flow}

As the sub-cooling level increases, surface tension driven flow is enhanced due to larger temperature gradients. In the calculation, bubble contact angle is selected as $55^{\circ}$. Both the radial and tangential velocities along bubble interface increase with sub-cooling level as shown in Fig. 30and Fig. 31. Fig. 32 shows the boron concentration profile along the bubble interface under different sub-cooling levels. The larger the sub-cooling level, the higher the maximum concentration. The maximum boron concentration factor changes with sub-cooling level almost linearly 
as shown in Fig. 33. In $90^{\circ} \mathrm{C}$ sub-cooling, the maximum concentration factor reaches about 6.5. This boron concentration does not reach the solubility limit to precipitation.

\section{CONCLUTIONS}

In this study, a hemispherical bubble model has been extended to a real bubble model. Surface tension driven flows and boron concentration fields around the bubble under sub-cooled boiling with constant wall temperature are obtained numerically. A reference case has been employed and some parameters have been discussed. The main conclusions drawn from this study are:

1. Boron concentrations vary along the bubble interface due to the phase change of water. Maximum boron concentration is located at the intersection of bubble interface and heated wall.

2. Maximum boron concentration increases as bubble contact angle decreases. It increases with liquid sub-cooling level almost linearly.

3. Boron precipitation does not occur under surface tension driven flow with mass transfer along the bubble interface in an 1800ppm boric acid solution.

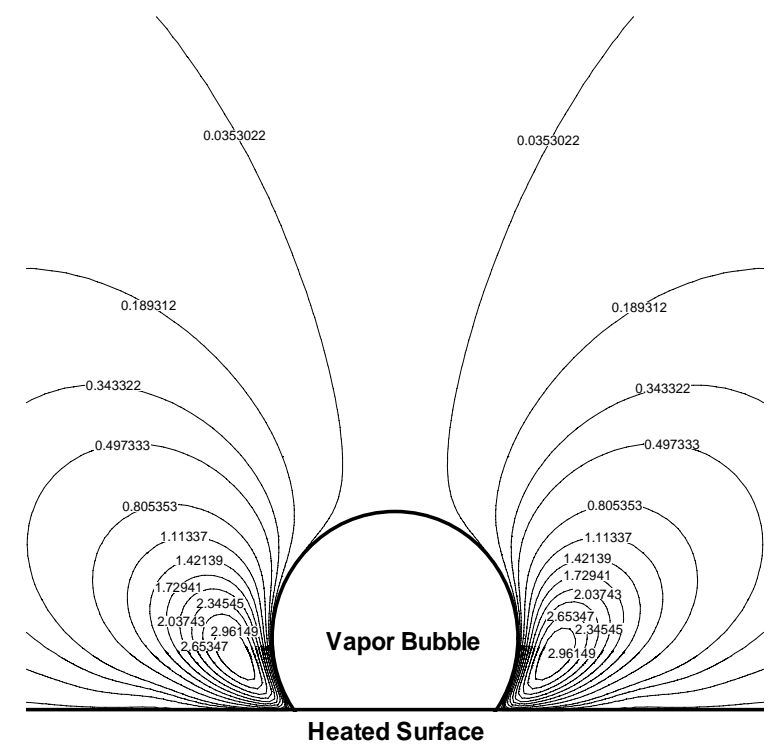

Fig. 24. Flow field around bubble under sub-cooled boiling 


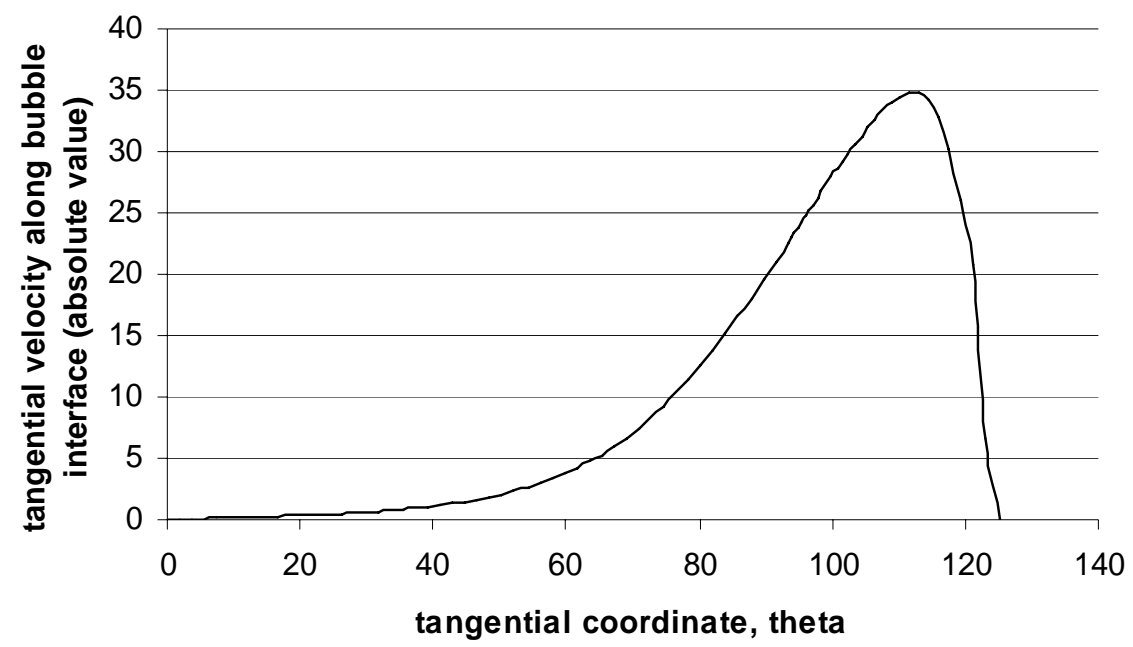

Fig. 25. Tangential velocity (absolute value) profile along the bubble interface

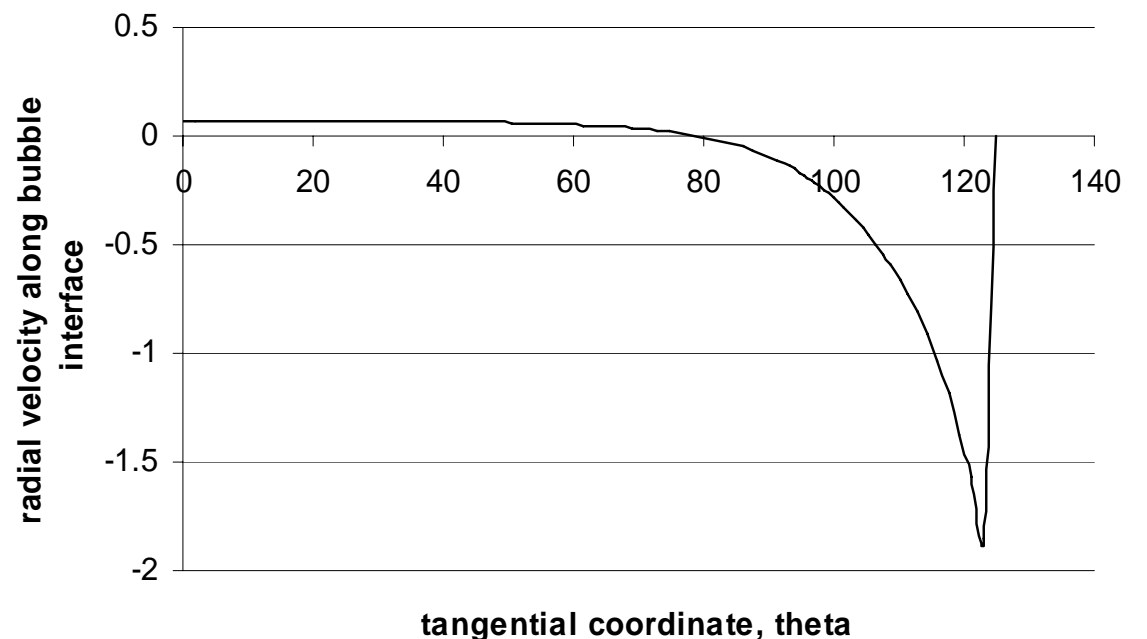

Fig. 26. Radial velocity profile along the bubble interface 


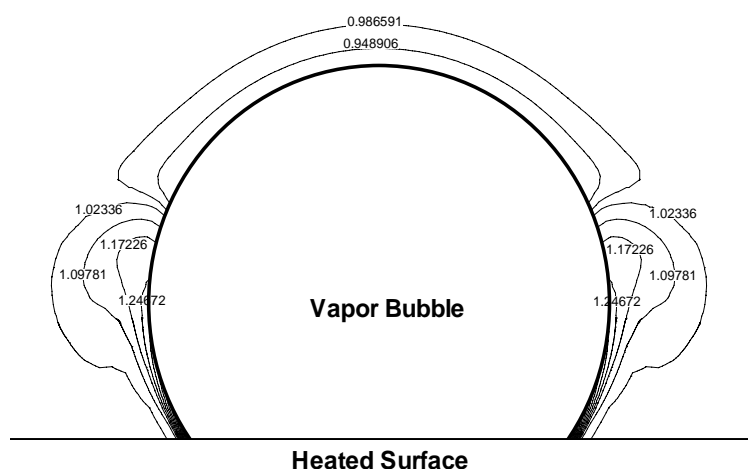

Fig. 27. Boron concentration distribution around bubble under sub-cooled boiling

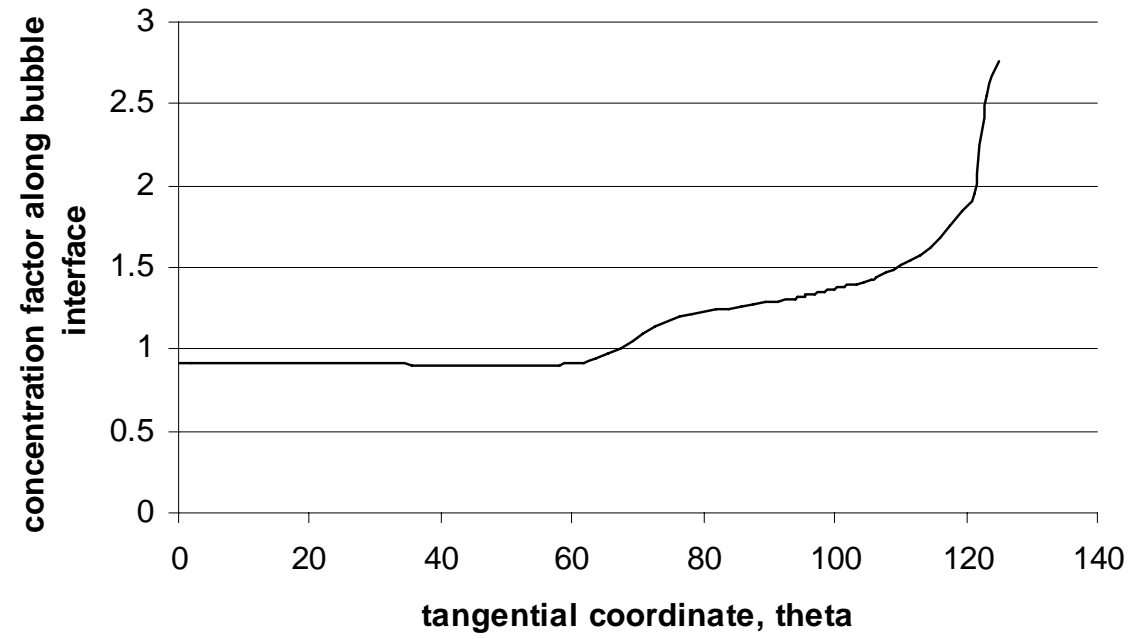

Fig. 28. Boron concentration profile along the bubble interface 


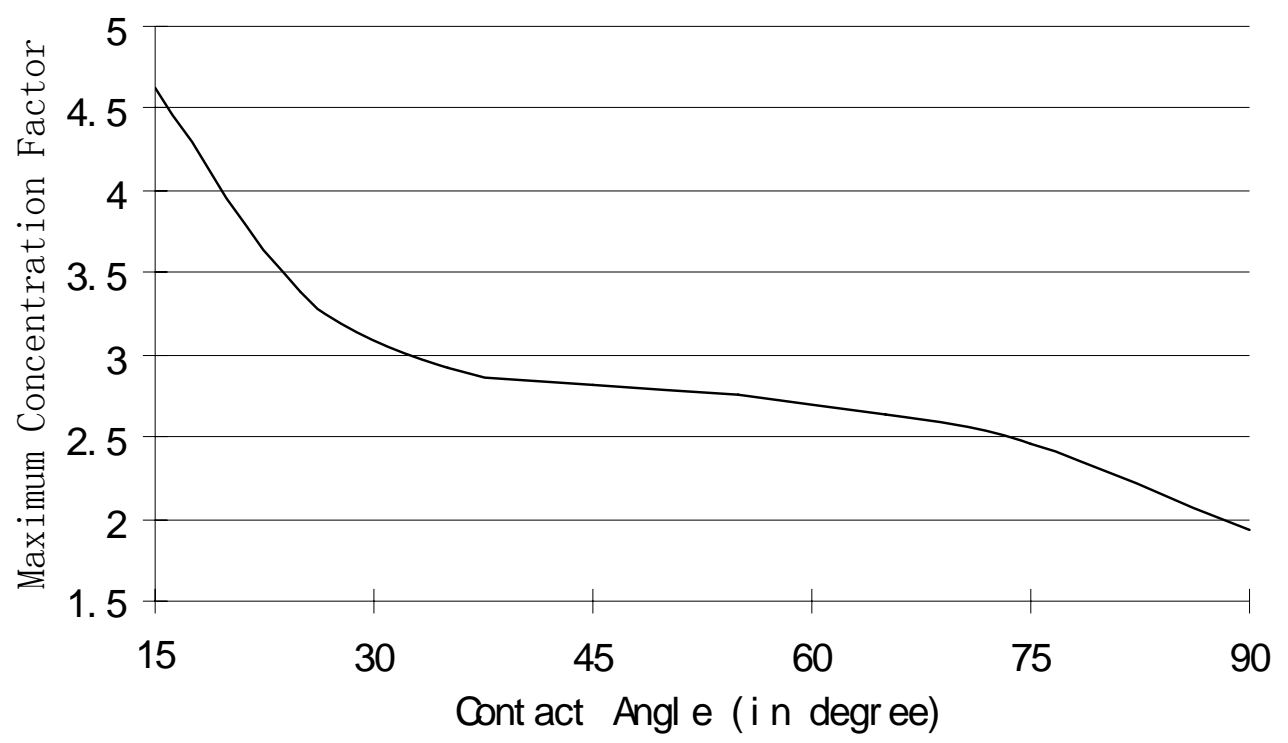

Fig. 29. Maximum Boron Concentration Factor Vs Bubble Contact Angle

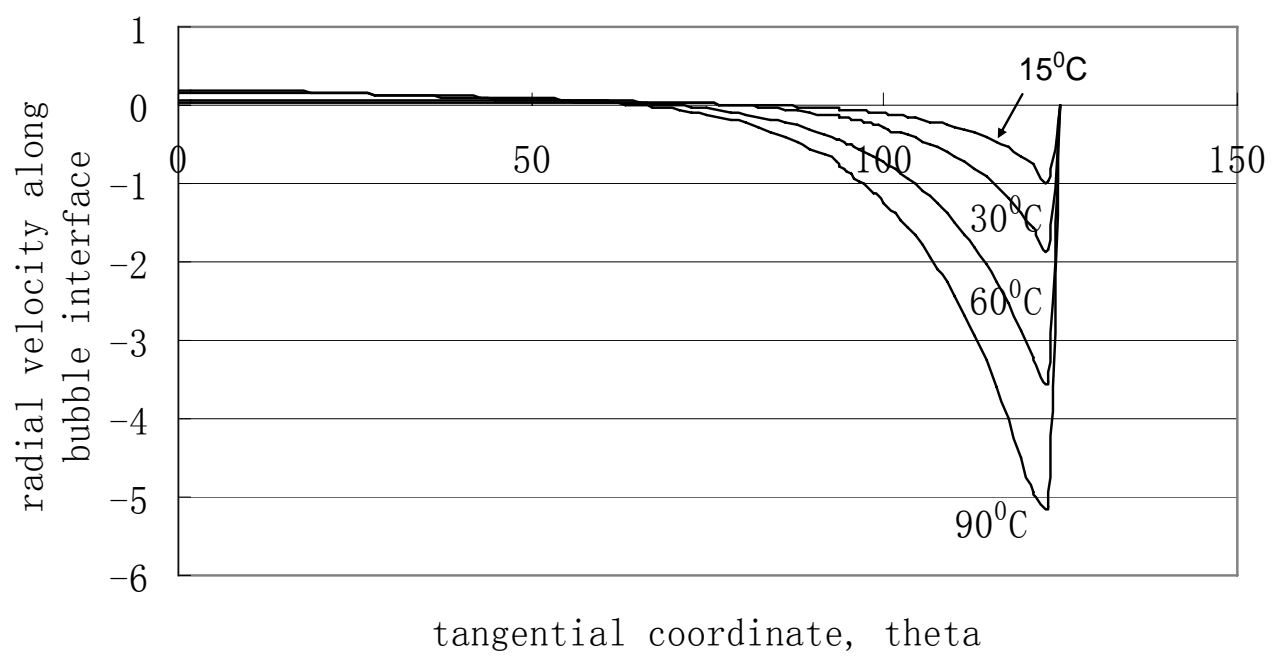

Fig. 30. Radial velocity along the bubble interface under different sub-cooling levels 


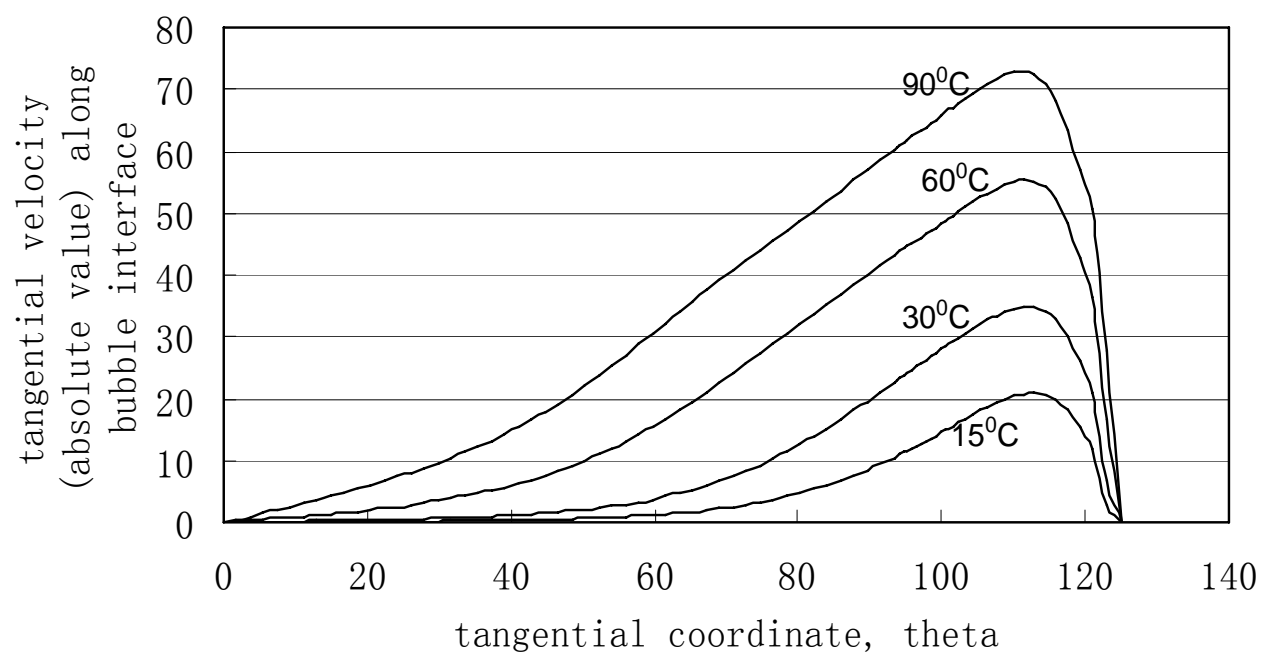

Fig. 31. Tangential velocity along the bubble interface under different sub-cooling levels

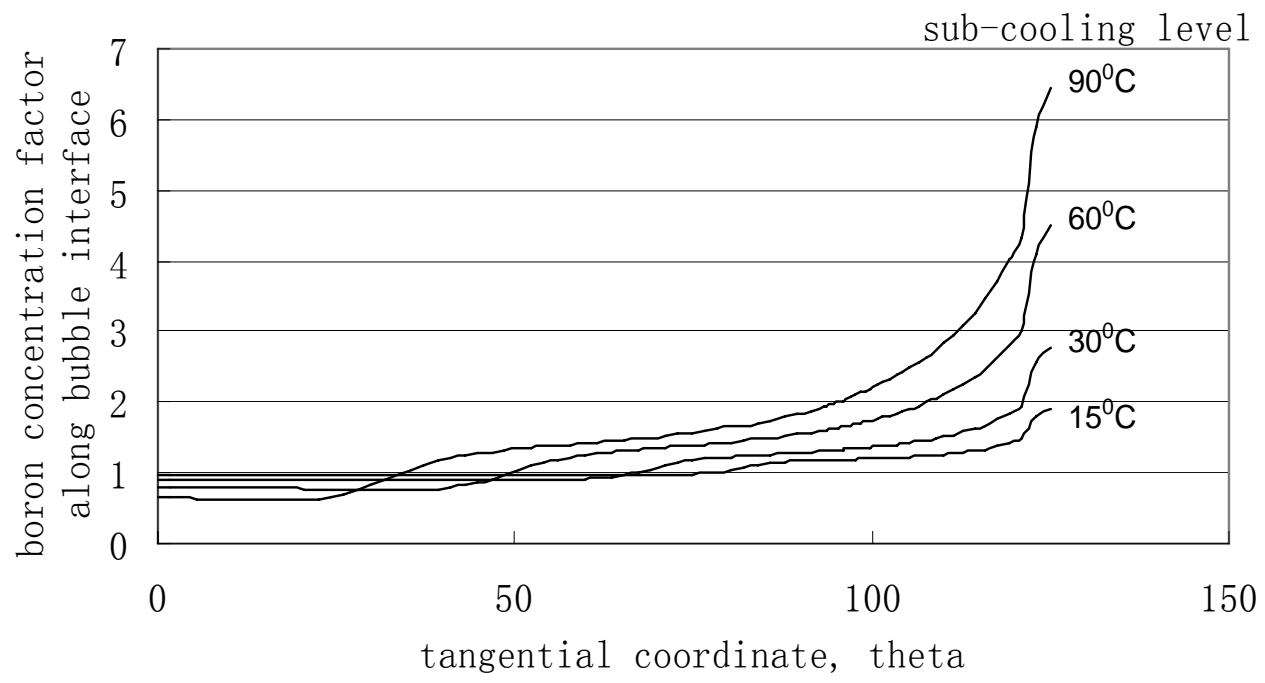

Fig. 32. Boron concentration factor along the bubble interface under different sub-cooling levels 


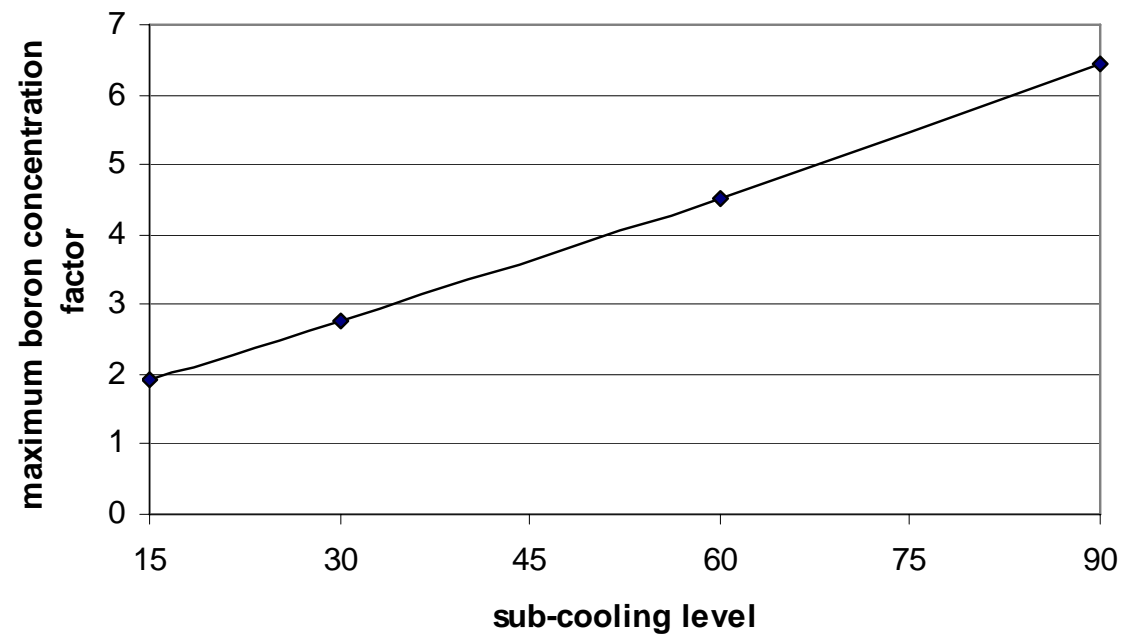

Fig. 33. Maximum Boron Concentration factor Vs sub-cooling level

\section{B-b)}

\section{Boron Holdup Mechanisms}

There are three possible boron holdup mechanisms in the porous crud layer. First, through mass convection the holdup of high concentrations of thermal neutron absorbing ${ }^{10} \mathrm{~B}$ in solution or in solid compounds in the crud layer causes the AOA described above. There are two solute transport mechanisms affecting the behavior of porous layer deposits: molecular pore diffusion and mass convection. Molecular pore diffusion results from solute concentration gradients in the crud layer while mass convection is induced from boiling due to high heat flux from the fuel rod. Fig. 34 shows the predicted concentration distribution of $\mathrm{H}_{3} \mathrm{BO}_{3}$ with depth in a $100 \mu \mathrm{m}$ thick porous crud layer. The steep exponential increase of $\mathrm{H}_{3} \mathrm{BO}_{3}$ possibly could lead to a precipitated deposit toward the bottom of the porous crud layer [12]. This model predicts boron holdup in the crud similar to that estimated from Secker's neutronic calculations of ${ }^{10} \mathrm{~B}$ holdup required to cause the observed AOA [13]. 


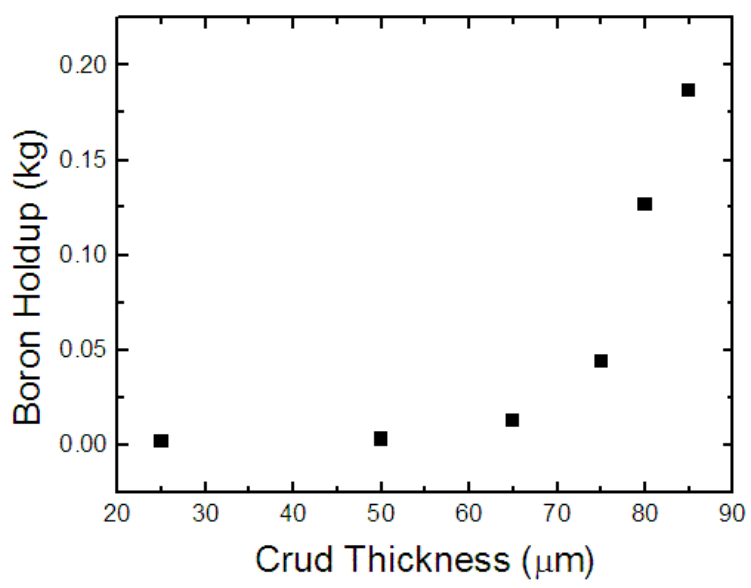

Fig. 34. Calculated boron holdup for typical crud thickness at $4000 \mathrm{MWD} / \mathrm{MTU}$ fuel burn up based on data from Callaway Cycle 9.

Second, Adsorption can possibly add to ${ }^{10} \mathrm{~B}$ mass hideout in the crud layer, and which can contribute to AOA. Boron has an affinity for adsorption onto corrosion products and Boron is held up by physi-sorption. The Langmuir model for competitive adsorption, introduced by Fletcher, explains the adsorption of boron compounds from $\mathrm{H}_{3} \mathrm{BO}_{3}$ solutions onto metallic oxides of porous crud layers [14]. In the model, $\mathrm{H}_{3} \mathrm{BO}_{3}$, $\mathrm{B}(\mathrm{OH})_{4}{ }^{-}$, and $\mathrm{OH}^{-}$compete for the adsorption sites (i.e. the surface molecules) on the surfaces of micropores in the crud.

Finally, crud deposits on the fuel pin clad can incorporate Bonaccordite $\left(\mathrm{Ni}_{2} \mathrm{FeBO}_{5}\right)$ within the layer [15]. Because multi-layer adsorption of boron takes places on magnetite, it is possible to involve formation of borate surface complexes. Adsorption on $\mathrm{NiFe}_{2} \mathrm{O}_{4}$ is a possible pathway for Bonaccordite, $\mathrm{Ni}_{2} \mathrm{FeBO}_{5}[16]$. Because this process is not well understood, further chemical analysis is needed to identify and quantify coupled behaviors.

\section{Radiolysis}

The interaction of high LET radiation with water, such as $\alpha$-particles and fast neutrons, forms molecular species $\left(\mathrm{H}_{2}, \mathrm{O}_{2}, \mathrm{H}_{2} \mathrm{O}_{2}\right)$ and of low LET radiation, such as $\gamma$-rays and electrons, forms radical species $\left(\mathrm{e}_{\mathrm{aq}}^{-}, \mathrm{H}^{+}, \mathrm{OH}^{-}, \mathrm{HO}_{2}^{-}\right)$. Species yields from radiolysis of water are functions of ${ }^{10} \mathrm{~B}$ concentration level of boric acid $\left(\mathrm{H}_{3} \mathrm{BO}_{3}\right)$, as well as of dissolved hydrogen $(\mathrm{DH})$, lithium hydroxide $(\mathrm{LiOH}), \mathrm{pH}$, temperature, and metallic impurities in the bulk coolant.

During the fuel cycle, the concentration of ${ }^{10} \mathrm{~B}$ is high at the beginning of the cycle and gradually decreases to a low level at the end of the cycle. High levels of $\mathrm{H}_{3} \mathrm{BO}_{3}$ are injected to stop fission reactions for shut down during refueling operations. During power operations, high ${ }^{10} \mathrm{~B}(\mathrm{n}, \alpha)^{7} \mathrm{Li}$ reaction rates cause an increase of water decomposition by energetic $\alpha$-particle radiolysis [17]. Thus, ${ }^{10} \mathrm{~B}$ removal by the 
transmutation reaction below reduces the ${ }^{10} \mathrm{~B}$ enrichment fraction in the bulk coolant.

$$
{ }^{10} \mathrm{~B}+\mathrm{n}_{\text {thermal }} \rightarrow{ }^{7} \mathrm{Li}+\alpha+2.35 \mathrm{MeV}
$$

Throughout the cycle, water is radiolytically decomposed regardless of $\mathrm{H}_{3} \mathrm{BO}_{3}$ concentration that provides the required quantity of ${ }^{10} \mathrm{~B}$. Thus, an understanding of local concentration levels of ${ }^{10} \mathrm{~B}$ and radiolysis products $\left(\mathrm{H}_{2}, \mathrm{O}_{2}\right.$, and $\left.\mathrm{H}_{2} \mathrm{O}_{2}\right)$ within the porous crud layer may provide insight into the conditions leading to crud growth on the fuel pin clad and its relation to AOA.

The results of the simulation are not coupled with source terms from gamma and fast neutron radiolysis, radiolysis from ${ }^{10} \mathrm{~B}(\mathrm{n}, \alpha){ }^{7} \mathrm{Li}$ reactions, and corrosion processes of the Zircaloy cladding. Particularly radiolysis from ${ }^{10} \mathrm{~B}(\mathrm{n}, \alpha)^{7} \mathrm{Li}$ reactions and corrosion processes may play important roles. During reactor operations, high ${ }^{10} \mathrm{~B}(\mathrm{n}$, $\alpha)^{7} \mathrm{Li}$ reaction rates cause an increase of water decomposition by energetic $\alpha$-particle radiolysis. Thus, ${ }^{10} \mathrm{~B}$ removal by the transmutation reaction reduces the ${ }^{10} \mathrm{~B}$ fraction in the porous oxide deposit.

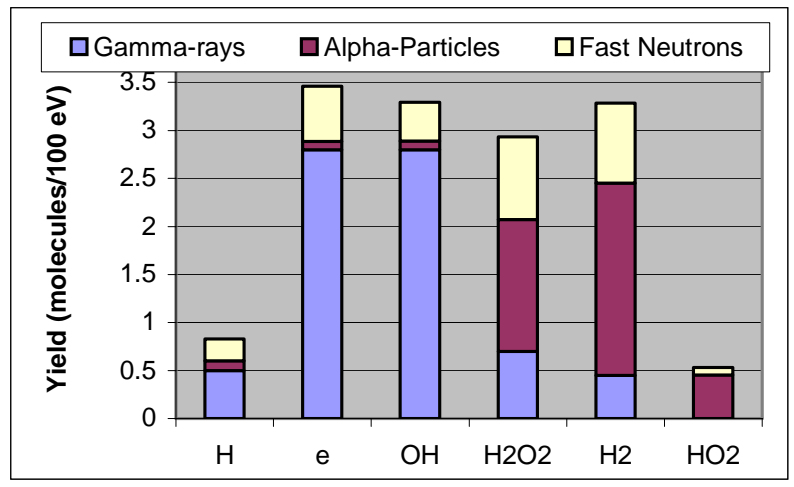

Fig. 35. Yields of radiolysis products at $\mathrm{pH} 7$ vs. Radiation Types [26]

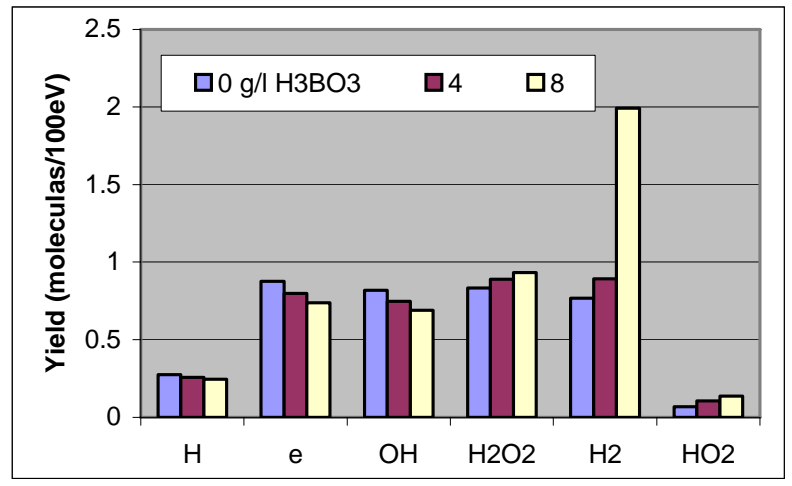

Fig. 36. Yields of radiolysis products at $\mathrm{pH} 7$ vs. Boric Acid concentrations [26] 
It is necessary to address the effect of the radiolysis of water in the presence of boric acid $\left(\mathrm{H}_{3} \mathrm{BO}_{3}\right)$ [17]. According to [26], the total yields of water radiolysis in the fuel core of the WWER-440 reactor depend on the concentration of boric acid and radiation types as shown in Fig. 35 and Fig. 36 [26]. The yields of radical species decrease with increasing $\mathrm{H}_{3} \mathrm{BO}_{3}$ concentration, while those of species such as $\mathrm{H}_{2}$, $\mathrm{H}_{2} \mathrm{O}_{2}$, and, particularly $\mathrm{HO}_{2}$ increase. Oxidizing radiolysis products such as $\mathrm{O}_{2}^{-}, \mathrm{HO}_{2}^{-}$, $\mathrm{OH}^{-}, \mathrm{H}_{2} \mathrm{O}_{2}$, and $\mathrm{O}_{2}$ participate strongly in the corrosion process. Long-lived products, especially $\mathrm{H}_{2} \mathrm{O}_{2}$ and $\mathrm{O}_{2}$, (particularly $\mathrm{H}_{2} \mathrm{O}_{2}$ ), make the maximum contribution to the corrosion processes [29].

\section{Solute transport of $\mathrm{H} 2, \mathrm{O} 2$, and $\mathrm{H} 2 \mathrm{O} 2$}

We have developed a time dependent Monte Carlo random walk methodology for the simulation of the transport of radiolysis products in the PWR crud layer. Transient solute transport of the two radiolysis products, molecular hydrogen $\left(\mathrm{H}_{2}\right)$ and oxygen $\left(\mathrm{O}_{2}\right)$, have been investigated [24]. This analysis considered two kinds of solute transport mechanisms in the layer: molecular diffusion and mass convection. It showed that molecular diffusion dominates over mass convection in the porous crud layer [12]. For this reason, we considered the simulation of the transient Diffusion Equation describing the solute concentration $C(r, z, t)$ associated with a cylindrical geometry model without a source term:

$$
D \nabla^{2} C(r, z, t)=\frac{\partial C(r, z, t)}{\partial t}
$$

where $D$ is the diffusion coefficient.

The preliminary transient results of the numerical approach show that the $\mathrm{H}_{2}$ species dominates in the upper portion, $\sim$ upper 10 to 20 percent, of the thick porous crud region as shown in Fig. 37 [24]. A rapid decrease of the $\mathrm{H}_{2}$ concentration with depth from the crud-bulk coolant interface is observed. The concentration distribution of $\mathrm{O}_{2}$ by molecular diffusion, however, shows the opposite behavior of $\mathrm{H}_{2}$. Most of the $\mathrm{O}_{2}$ exists in the lower portion, $\sim$ lower 80 to 90 percent, of the porous region with a rapid increase of concentration with depth from the crud-bulk coolant interface as shown in Fig. 38 .

Future work, thus, will investigate the concentration of the radiolysis products $\mathrm{H}_{2}, \mathrm{O}_{2}$, and, $\mathrm{H}_{2} \mathrm{O}_{2}$ in porous crud layer through the solute transport model with the transient Monte Carlo numerical technique. 


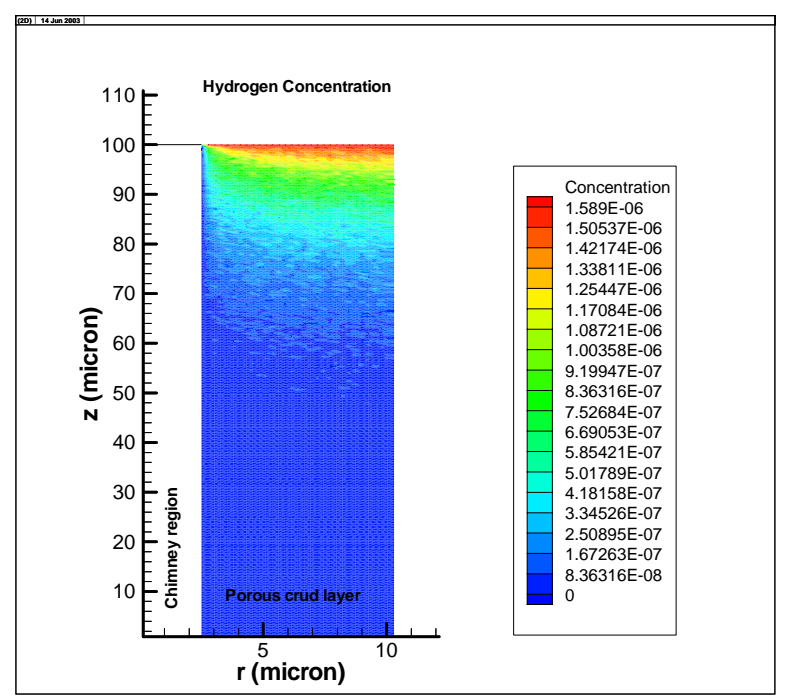

Fig. 37. $\mathrm{H}_{2}$ concentration distribution in $\mathrm{g} \mathrm{H}_{2} / \mathrm{cm}^{3}$ with 100 random walks and equilibrium state.

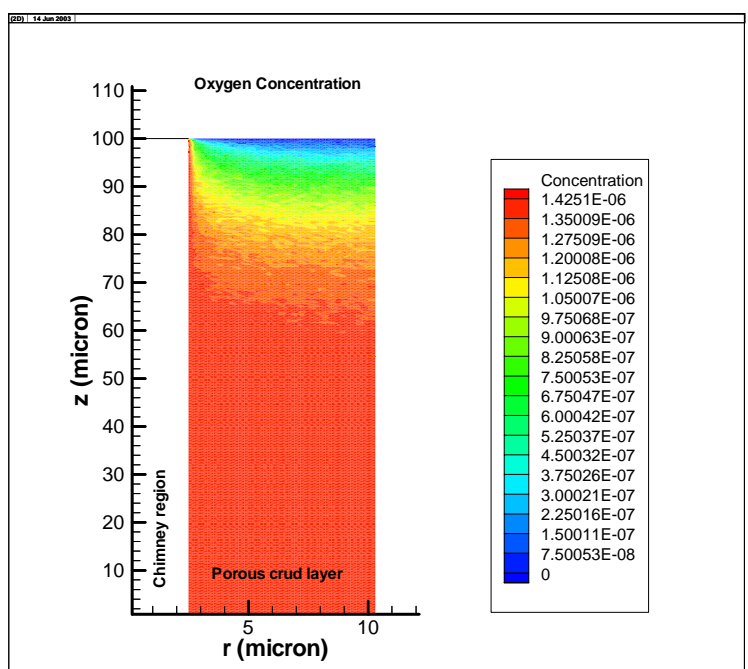

Fig. 38. $\mathrm{O}_{2}$ concentration distribution in $\mathrm{g} \mathrm{O}_{2} / \mathrm{cm}^{3}$ with 200 random walks and equilibrium state condition

It is essential to understand the crud growth and the electrochemical kinetics of these species at the clad/crud, crud/coolant interfaces, or within the crud layer deposit under the presence of radiolysis. The modified numerical model, therefore, will be considered to be a Diffusion Equation with a transient term and source terms from the radiolysis and corrosion processes. The random walk Monte Carlo technique will be employed to simulate this problem in the transient regime with a powerful capability to handle source terms from radiolysis and corrosion of the fuel cladding. Finally, the model will be incorporated with source terms as proposed in the following equation:

$$
D \nabla^{2} C(r, z, t)+S=\frac{\partial C(r, z, t)}{\partial t}
$$




\section{Discussion}

For reactor fuel clad, it is known that the initial oxidation stage results in the formation of a thin protective black oxide film. It is nonstoichiometric, $\mathrm{ZrO}_{2-\mathrm{x}}$, due to oxygen deficiency. Its thickness usually does not exceed $3 \mu \mathrm{m}$. When the oxygen concentration in the film reaches stoichiometry, the solid $\mathrm{Zr}-\mathrm{in}-\mathrm{ZrO}_{2}$ solutions transform into white $\mathrm{ZrO}_{2}$. Unlike $\mathrm{ZrO}_{2-\mathrm{x}}, \mathrm{ZrO}_{2}$ does not possess protective properties. This white porous film grows on the black film. This change is termed "transition" in

the corrosion process. Post-transition growth obeys a linear law for its increment, and the oxidation rate is almost constant [25].

Johnson's "thick oxide film hypothesis" suggests a possible explanation for the linear growth law of the post-transition stage [27, 28]. It hypothesizes that after the oxide on Zircaloy fuel cladding reaches a threshold thickness, the subsequent oxidation rate is restricted by water radiolysis in oxide cracks and pores. Therefore, radiolysis within this thick porous oxide (or crud) is independent of the water chemistry in the bulk coolant. It is dominated by highly localized water chemistry near the metal-oxide interface. Such a hypothesis can be supported by the results from the experiments on Zircaloy pressure tubes in the Hanford Site N Reactor core and low-temperature ex-reactor (autoclave).

Future research may examine how the electroactive radiolysis species formed during water radiolysis at the crud/cladding interface affect the corrosion processes of fuel cladding, and from this obtain understanding of how radiation and water chemistry influence crud deposition and corrosion of the Zircaloy cladding under subsequent boron hide-out in a prototypical condition.

For modeling studies of the solute transport of radiolysis products, a transient random walk Monte Carlo simulation is proposed to address this problem by considering source terms from gamma and fast neutron radiolysis and high LET induced radiolysis from ${ }^{10} \mathrm{~B}(\mathrm{n}, \alpha)^{7} \mathrm{Li}$ reactions. Corrosion processes within the Zircaloy fuel cladding are possibly explained by the thick oxide film effect on the cladding. Therefore, the solute transport of $\mathrm{H}_{2}, \mathrm{O}_{2}$, and $\mathrm{H}_{2} \mathrm{O}_{2}$ should be investigated. These are the most stable radiolysis products that directly affect the oxidation-reduction reactions at the interface of metal/oxide, particularly under the thick oxide layer with corrosion products such as $\mathrm{Ni}, \mathrm{Fe}, \mathrm{Cr}$, and $\mathrm{Zr}$. 


\section{REFERENCE}

1. Estimation of the solute concentration factor in the crud layer, personal communication with Xu Li, SUNY, stonybrook, NewYork, 2000.

2. Barclay G. Jones, Chin Pan and Jyi-Yu Sun, a study of wick boiling phenomena in porous deposits, EPRI-WB-1,(RP-125-08), 1984.

3. Data Set of Callaway Cycle 9 ( $6000 \mathrm{MWD} / \mathrm{MTU}$ ), private communication with Dr. Michael Young, Westinghouse Electric Company, 2000.

4. Data Set of Callaway Cycle 9 ( $4000 \mathrm{MWD} / \mathrm{MTU}$ and $8000 \mathrm{MWD} / \mathrm{MTU}$ ), private communication with Dr. Michael Young, Westinghouse Electric Company, 2000.

5. Personal communication with Dr. Kenneth Burrill, Atomic Energy of Canada, Ltd. Chalk River, 2000.

6. Paul Cohen, water coolant technology of power reactors, 1980.

7. F. C. Kracek, G.W. Morey and H.E. Merwin, the system, water-Boron oxide, 1938.

8. D. Zhou and B. G. Jones, "Boron Concentration Model and Effects of Boron Holdup on Axial Offset Anomaly (AOA) in PWRs," ICONE-10-22636, 2002.

9. Barclay G. Jones, Chin Pan and Jyi-Yu Sun, 1984 ,"A Study of Wick Boiling Phenomena in Porous Deposits," EPRI-WB-1,(RP-125-08).

10. P. Cohen, "Heat and Mass Transfer for Boiling in Porous Deposits with Chimneys," AICheE Symposium Series, Vol. 70, No. 138, pp. 71-80, 1974.

11. M. Jakob, Heat Transfer, John Wiley and Sons, New York, NY, 1949.

12. H. Joe, "Study of water radiolysis effects on transport of solute and related chemical reactions in porous crud," MS thesis, University of Illinois at Urbana-Champaign (2002).

13. J. R. Secker, Y. A. Shatilla, M. Y. Young, and Y. Sung, "Methods for Evaluating Crud Induced Axial Power Shift", ANS Annual Meeting, 2001.

14. W. D. Fletcher, Interactions between Stainless Steel Corrosion products and Boric Acid solutions, WCAP-3730, Westinghouse Electric Corporation Report, March, 1964.

15. P. L. Frattini, J. Blok, S. Chauffriat, J. Sawicki, and J. Riddle, “Axial offset anomaly: Coupling PWR primary chemistry with core design", Nuclear Energy, vol. 40, No. 2, pp 123-135, 2001.

16. EPRI Report, 2002, “Adsorption of Boric Acid on Synthetic Fuel Crud Oxides," EPRI Report TR-1003384.

17. Marangoni, C. S. M. and Stefanilli, P., 1872, "Monografia Sulle Bolle Liquide", I1 Nuovo Cimento, serie 2a., 7-8, pp. 301(see in the same volume the discussion by M.I. Plateau at page 370 )

18. Larkin, B.K., "Thermocapillary Flow Around Hemispherical Bubble”, AIChEJ, Vol.16, No.1, pp. 101-107, Jan. 1970

19. Kao, Y. S. and Kenning, D.B.R., "Thermocapillary Flow Near a Hemispherical Spherical Bubble on a Heated Wall”, Journal of Fluid Mechanics, Vol. 53, part 4, pp. 715-735, 1972

20. Jabardo, J.M.S., "Investigation of Thermocapillary Flows Around Hemispherical 
Bubbles", Ph.D. Thesis, University of Illinois at Urbana-Champaign, 1982

21. Rao, Q.Y., Jones, B.G., "Study of Mechanism of Initial Crud Formation on Fuel Cladding in Sub-Cooled Boiling Region in PWR", ICONE10-22558, April 2002, Virginia

22. Bai, Q., Dhir, V.K., "Numerical Simulation of Bubble Dynamics in the Presence of Boron in the Liquid", 2001 ASME IMECE/AMD, Nov. 2001, New York

23. B. Pastina, J. Isabey, and B. Hickel, " The influence of water chemistry on the primary coolant water in pressurized water reactors," Journal of Nuclear Materials, Vol. 264, pp. 309-318, 1999.

24. Joe, H., Jones, B. G., and M. Ragheb, 2003, "Axial Offset Anomaly and Radiolysis Product Transport in PWRs Fuel Assembly Crud Layer,” ANS Winter Meeting Transactions.

25. Kritsky, V.G., 1999, Water Chemistry and Corrosion of Nuclear Power Plant Structural Materials, American Nuclear Society, La Grange, IL.

26. Gordeev, A. V., Ershov, B. G., 1991, "Calculations of the Yields of Water Radiolysis Products in a Nuclear Reactor," Radiation Physics and Chemistry, Vol. 38, No. 1, 133-134.

27. Hillner, E., Franklin, D.G., Smee, J.D., 2000, "Long-term Corrosion of Zircaloy before and after Irradiation", Journal of Nuclear Materials, Vol. 278, 334-345.

28. Lanning, D.D., Johnson, A. B. Jr., Trimble, D.J., and Boyd, S.M., 1989, "Corrosion and Hydriding of N Reactor Pressure Tubes, Zirconium in the Nuclear Industry," Eighth International Symposium, American Society for Testing and Materials, 3-19.

29. Nishino, Y., Endo, M., Ibe, E., and Yasuda, T., 1997, "Formation and Dissolution of Oxide Film on Zirconium Alloys in $288^{\circ} \mathrm{C}$ Pure Water under $\gamma$-ray Irradiation," Journal of Nuclear Materials, Vol. 248, 292-298. 


\section{PUBLICATIONS}

1. Zhou, Dawei and Barclay G. Jones, "Computational Model for Evaluating Boron Holdup and Axial Offset Anomaly (AOA) in PWRS," American Nuclear Society Annual Meeting, Hollywood, FL, 2002. (June 9-13)

2. Joe, Hyun-Jong and Barclay G. Jones, "Modeling of Porous Crud Layer Based on Diffusion and Radiolysis," American Nuclear Society Annual Meeting, Hollywood, FL, 2002. (June 9-13)

3. Rao, Qinyang and Barclay G. Jones, "Numerical Simulation of Initial Crud Formation and Fuel Cladding in Subcooled Boiling Region in PWR," American Nuclear Society Annual Meeting, Hollywood, FL, 2002. (June 9-13)

4. Wu, Wen and Barclay G. Jones, "Flow Field and Bubble Dynamics Simulation in Subcooled Region in PWRs," American Nuclear Society Annual Meeting, Hollywood, FL, 2002. (June 9-13)

5. Radhakrishnan, Srinivasan and Barclay G. Jones, "Use of Enriched Boric Acid as Chemical Shim and Effect on B10 Holdup from Contributing Mechanisms," American Nuclear Society Annual Meeting, San Diego, CA, 2003. (June 1-5)

6. Joe, Hyun-Jong and Barclay G. Jones, "Crud Formation and Effects of Corrosion, Heat Flux, and Radiation," American Nuclear Society Winter Meeting, November, 2003

7. Joe, Hyun-Jong, Barclay G. Jones and Magdi Ragheb, "Axial Offset Anomaly and Radiolysis Product Transport in PWRs Fuel Assembly Crud Layer," American Nuclear Society Annual Meeting, San Diego, CA, 2003. (June 1-5)

8. Joe, Hyun-Jong and Barclay G. Jones, "Considerations for Using Enriched Boric Acid in PWR Primary Coolant," American Nuclear Society Annual Meeting, San Diego, CA, 2003. (June 1-5)

9. Zhou, Dawei and Barclay G. Jones, "Boron Concentration Model and Effects of Boron Holdup on Axial Offset Anomaly (AOA) in PWRs," ICONE-10-\#22636, Tenth International Conference on Nuclear Engineering, Arlington, Virginia, 2002. (April 15-19)

10. Joe, Hyun-Jong and Barclay G. Jones, "Modeling of Porous Crud Layer Based on Effects of Diffusion and Water Radiolysis on Anomalous Porous Crud Deposition on Fuel Pin Surfaces in PWRs," ICONE-10-\#22602, Tenth International Conference on Nuclear Engineering, Arlington, Virginia, 2002. (April 15-19)

11. Rao, Qinyang and Barclay G. Jones, "Study of Mechanism of Initial Crud Formation on Fuel Cladding in Subcooled Boiling Region in PWR," ICONE-10-\#22558, Tenth International Conference on Nuclear Engineering, Arlington, Virginia, 2002. (April 15-19)

12. Wu, Wen and Barclay G. Jones, "Simulation of Bubble Dynamics in Sub-cooled Boiling on Fuel Clad in PWRs," ICONE-10-\#22682, Tenth International Conference on Nuclear Engineering, Arlington, Virginia, 2002. (April 15-19)

13. Radhakrishnan, S. and Barclay G. Jones, "Axial Offset Anomaly: Effect of using Enriched Boric Acid as chemical shim on B10 holdup in crud", ICONE-11-\#36554, Eleventh International Conference on Nuclear Engineering, Tokyo, Japan, 2003 (April 20-23) 
14. Joe, Hyun-Jong and Barclay G. Jones, "Crud Formation and Effects on Corrosion, Heat Flux, and Radiation on Zircaloy Cladding “, ICONE 11-\#36355, Eleventh International Conference on Nuclear Engineering, Tokyo, Japan, 2003 (April 20-23) 